\title{
La Real Sociedad Económica Matritense de Amigos del País durante la dominación francesa (1808-1813) ${ }^{1}$
}

\author{
Elisa Martín-Valdepeñas Yagüe \\ DEA en Historia Contemporánea UNED
}

The Madrid Royal Economic Society during the Peninsular War (1808-1813)

\begin{abstract}
RESUMEN
La Sociedad Económica Matritense de Amigos del País colaboró activamente para difundir el ideario ilustrado y desarrolló un programa de progreso en los ámbitos educativo, económico y social. Desde su fundación en 1775 se benefició de su cercanía al poder político. Durante la Guerra de la Independencia, la corporación permaneció abierta, a pesar de que la situación de la ciudad de Madrid no era la más adecuada para el desarrollo de sus tareas. En los primeros años de la guerra, gracias a la actividad de unos pocos socios, pudo sobrevivir a duras penas de manera independiente. A finales

de 1809 los afrancesados se fijaron en ella y apoyaron decididamente a la corporación con el objetivo de captar a ciertas minorías sensibles a los proyectos modernizadores. Sin embargo, no pudieron alcanzar plenamente su propósito de propaganda por la falta de una financiación adecuada.
\end{abstract}

\begin{abstract}
The Economic Society of Madrid (Real

Sociedad Económica Matritense de Amigos del País) collaborated actively to spread the Illustration ideas and developed a program to progress in educative, economic and social scopes. Since its foundation in 1775 , the Society was benefited from its proximity to the political power. During the Peninsular War, the corporation remained open. However, the city of Madrid was not in an appropriated situation for developing its tasks. Due to the activity of a few partners, the Society could survive with great difficulty in a self-sufficient way, during first years of war. At the end of 1809 frenchified Spaniards (afrancesados) paid attention to it and definitely supported the Society. The aim was to catch some sensible minorities for collaborating in modernizing projects. Nevertheless, they could not totally reach their propaganda intentions by lacking of a suitable financing.
\end{abstract}

1 Este artículo es una síntesis del trabajo de investigación inédito dirigido por la profesora Blanca Buldain Jaca, presentado en el Departamento de Historia Contemporánea: La Real Sociedad Económica Matritense de Amigos del País durante la dominación francesa (1808-1813), UNED, Madrid, 2006. 
PALABRAS CLAVE: Real Sociedad Económica Matritense de Amigos del País, Guerra de la Independencia, José I, Afrancesados.
KEYWORDS:

Economic Society of Madrid, Peninsular

War, King Jose I, Frenchified Spaniards.

\section{INTRODUCCIÓN}

La fundación de las Sociedades Económicas de Amigos del País constituyó una de las novedades más emblemáticas de la llustración. Concebidas desde los círculos reformadores como un instrumento que actuase a favor del fomento económico y del desarrollo cultural, estas corporaciones sobresalieron en el panorama científico e intelectual de la España del último tercio del siglo XVIII. La primera de ellas, la Real Sociedad Bascongada, surgió de la iniciativa de unos pocos ilustrados vascos reunidos en torno a la tertulia del conde de Peñaflorida en Azcoitia en 1765. Diez años más tarde, el espaldarazo oficial de Pedro Rodríguez de Campomanes contribuyó a su implantación por toda la geografía nacional. El apoyo de la monarquía fue determinante para su proliferación y, a la vez, la favorable acogida del Discurso sobre el fomento de la industria popular dio la pauta para canalizar de una manera coordinada las inquietudes de las minorías ilustradas repartidas por toda la nación.

La Real Sociedad Económica Matritense de Amigos del País se creó en 1775 por iniciativa directa de Campomanes. Pronto se convirtió en el modelo a seguir por el resto de estas instituciones, gracias al papel preponderante que se le concedió desde el propio gobierno. Colaboró activamente para difundir el ideario ilustrado y realizó un completo programa de progreso en los ámbitos económico, educativo y social, reclamado desde los sectores más renovadores.

A principios de 1808, la Matritense contaba con una larga trayectoria reformista. Había logrado convertirse en una institución prestigiosa que cooperaba con las autoridades en las cuestiones que, desde diferentes organismos, le solicitaban para su dictamen y mediante la administración de diversos establecimientos educativos y de beneficencia que tenía a su cargo. Aunque había perdido el dinamismo de sus mejores tiempos, cuando publicó unos extensos tomos de Memorias y bajo sus auspicios se imprimió el Informe sobre la Ley Agraria de Jovellanos, su actividad no había disminuido. Algunos de los más insignes personajes de la llustración española que habían formado parte de su catálogo de socios habían desaparecido, no obstante, nuevos miembros, procedentes de las clases medias y altas de la nación con inquietudes más avanzadas, habían tomado el relevo atraídos por su reputación y dispuestos a sumarse al esfuerzo modernizador que preconizaba².

2 Según el último recuento contaba con 181 socios efectivos (al corriente del pago de la contribución anual). ARCHIVO DE LA REAL SOCIEDAD ECONÓMICA MATRITENSE DE AMIGOS DEL PAÍS (ARSEM): A/110/33, Libro de Actas de las Juntas de la Sociedad (1806-1808), Junta de 29-8-1807. 
Con una existencia que ya alcanzaba un tercio de siglo, la Sociedad Económica de Madrid seguía fielmente la organización que se había fijado en sus Estatutos. La entidad se dividía en tres secciones o clases: Agricultura, Industria y Artes y Oficios, a las que se debían adscribir los nuevos miembros al incorporarse en función de sus preferencias o conocimientos. Los trabajos a desarrollar por la institución se realizaban en el seno de estas secciones y, en general, consistían en la censura de obras pendientes de publicación, el reconocimiento de inventos 0 adelantos técnicos, el estudio de las ordenanzas de los gremios, el examen de expedientes enviados por la secretaría de Estado o el Consejo de Castilla, la lectura de informes realizados por los propios socios y la revisión de las memorias que concurrían a los premios anuales.

Las clases de socios estaban establecidas en función de sus circunstancias. Las denominaciones habían variado después de diversas modificaciones parciales de los Estatutos, no obstante, pueden reducirse a cuatro categorías. Los socios protectores, benefactores de la institución, pertenecientes a la familia real. A principios de 1808 ostentaban dicha condición el rey Carlos IV, el príncipe de Asturias, Fernando, y los infantes Carlos María Isidro y Antonio Pascual. El nombre de numerario o contribuyente (la mayoría de socios) designaba a los que habitaban en Madrid. La denominación de correspondientes y agregados (vinculados a las sociedades agregadas a la Matritense) estaba constituida por aquellos que no residían en la capital. La cuota anual estaba fijada en 120 reales, obligatoria para todos los socios, excepto los «profesores sobresalientes", es decir, personas relevantes en algún campo científico, artístico o intelectual que recibían la distinción de socios de mérito ${ }^{3}$.

La Sociedad Matritense actuaba como un órgano colegiado y sus resoluciones se tomaban por mayoría en la junta general o de dirección. Ésta, abierta a todos los miembros de la corporación, se celebraba todos los sábados por la tarde en la Casa Consistorial madrileña, ya que el Ayuntamiento había cedido una sala para dichas reuniones. En dicha asamblea se aprobaban las actas de las sesiones de las clases, se revisaba la administración interna y se nombraban comisiones especiales para una misión concreta como la elaboración de discursos para determinadas autoridades, las representaciones dirigidas al rey, las visitas a los poderosos,... Además, la institución estaba representada en determinados organismos como la Junta de Caridad o el Colegio Académico de Primeras Letras y gestionaba diversos establecimientos de enseñanza o beneficencia como la Escuela de Taquigrafía o el Real Colegio de Sordomudos.

Cada año la Sociedad Económica madrileña otorgaba varios premios en metálico a las mejores memorias presentadas, a las experiencias agrícolas y a las inno-

\footnotetext{
${ }^{3}$ La exención del pago se hacía «en consideración á sus menores fondos, y á la necesidad de sus luces, y experiencias para cumplir debidamente el instituto». Real Cedula de S. M. y Señores del Consejo, en que se aprueban los Estatutos de la Sociedad económica de amigos del Pais, con lo demas que se expresa, á fin de promover la Agricultura, Industria y Oficios, Imp. Pedro Marin, Madrid, 1775, pág. 3.
} 
vaciones artesanales e industriales, según un programa previo publicado en la Gazeta de Madrid. A los agraciados se les podía conceder el título de socio de mérito. En la ceremonia pública de distribución de los galardones se invitaba a las instituciones más importantes de la capital. Tradicionalmente, se leía un informe de las actividades realizadas durante el año que, posteriormente, se presentaba a los reyes como muestra de respeto. En ocasiones, los discursos pronunciados incluían un Elogio a los monarcas o a los socios fallecidos. Los actos extraordinarios de la corporación, incluidos los exámenes anuales de los diferentes establecimientos educativos a su cargo, se publicaban habitualmente en forma de nota en la Gazeta ${ }^{4}$. Asimismo, en el mes de noviembre o diciembre de cada año se celebraban las elecciones para los cargos directivos, teniendo el derecho de voto y a ser propuestos como candidatos los socios que habían trabajado regularmente para la entidad durante ese periodo. El director y subdirector se renovaban anualmente y los restantes cada dos años, excepto el secretario cuyo mandato era de cuatro años ${ }^{5}$.

\section{LA SOCIEDAD MATRITENSE ANTE LA CRISIS POLÍTICA DE 1808}

La vorágine de acontecimientos del año 1808 condicionó la vida de la corporación, como ocurrió en otras instituciones artísticas o científicas. Los sucesos de Aranjuez y las abdicaciones de Bayona, así como las sucesivas ocupaciones de Madrid por los ejércitos, tanto franceses como españoles, alteraron sustancialmente la tranquilidad de la que hasta entonces había gozado. Por un lado, sufrió el ambiente de violencia que se vivía en las calles y, por otro, la represión a la que sometieron las autoridades francesas a los habitantes de la ciudad, especialmente tras el levantamiento del «dos de mayo». Sin embargo, a pesar de las dificultades vividas en la capital, la corporación pudo subsistir, afrontando las circunstancias con indiscutible determinación, aunque se encontraba desprovista prácticamente de recursos, abandonada por los socios y con un grado de actividad muy disminuido.

Tras unos primeros momentos de desconcierto, una vez digeridos los acontecimientos, en el seno de la institución comienzó a surgir el deseo de congraciarse con el poder. La necesidad de contar con el apoyo oficial para financiar los establecimientos educativos y de beneficencia que regentaba obligaba a una manifestación pública de adhesión a las nuevas autoridades. El día 9 de abril de 1808 se decidió la elaboración de una "Oracion gratulatoria por la exaltac" al trono del $\mathrm{S}^{r}$. Rey $\mathrm{D}^{\mathrm{n}}$. Fernando ${ }^{\circ} .^{\circ}$. Con este discurso se trataba tanto de rendir respetos

4 Muchos de estos Elogios se imprimieron. La última junta pública general de distribución de premios se celebró el 20-9-1807. ARSEM: A/110/33, Juntas de 19-9-1807 a 2-4-1808.

5 Manuel Godoy había ocupado la dirección desde 1792 a 1798 y en 1807. A finales de ese año, fue reelegido pero rechazó el cargo por sus múltiples ocupaciones. El nombramiento, tras una nueva votación, recayó en el duque de Híjar, subdirector en 1807. ARSEM: Idem, Juntas de 10-10-1807 a 30-11808. 
como de buscar la protección del nuevo poder establecido en consonancia con las prácticas determinadas por el Antiguo Régimen ${ }^{6}$. Por eso, intentaron reproducir los mismos actos que habían realizado tras la coronación de Carlos IV aunque, en este caso, la forma de acceder al solio del nuevo soberano cambiaba radicalmente. Un mes después, cuando ya habían trascendido las primeras noticias de las abdicaciones de Bayona, se suspendió dicho encargo «por haber variado las circunstanz $z^{s}$.». Manera un tanto curiosa de definir el desastre de la monarquía española sobrevenido entre marzo y mayo de 1808 .

Desde el 9 de abril, las juntas de la Sociedad Económica se interrumpieron durante un mes a causa de la coincidencia con la Semana Santa, durante la cual no estaba previsto su celebración, como había ocurrido de forma tradicional, y después por falta de concurrentes. La inquietud que se vivía en la ciudad desde principios de abril por el clima de turbulencia popular que las autoridades habían intentado sofocar con continuos llamamientos al sosiego público, disuadió a los socios de acudir a las reuniones semanales. La situación se iba volviendo cada vez más agitada en los días que precedieron al «dos de mayo» y la normalidad todavía tardaría en restablecerse después del levantamiento. Además, tampoco es extraño que los socios evitasen acudir a la junta semanal después de conocer el bando de Murat en el que se determinaba que «Toda reunión de más de ocho personas será considerada como una junta sediciosa y deshecha por la fusilería» ${ }^{7}$.

Calmados los ánimos, Murat se convirtió en el presidente de la Junta Suprema de Gobierno dejada por Fernando VII tras su marcha. Los objetivos de su mando se concretaron en apaciguar a la población, profundizar en la propaganda política pro-francesa y someter a las instituciones y a las autoridades con el propósito de controlar la situación. Por esta razón, a partir del día 9 de mayo el gran duque de Berg, convertido en Lugarteniente General del Reino, recibió prácticamente a todas las instituciones de la ciudad, en jornadas interminables en las que se reconocía el «poder del ocupante». Por su despacho desfilaron nobles, cuerpos colegiados, autoridades locales y personajes destacados ${ }^{8}$.

Ese mismo día se convocó a los socios de manera extraordinaria por la acumulación de asuntos pendientes de decisión que el secretario no estaba en condiciones de poder resolver por su cuenta. La Sociedad debía seguir funcionado. La ausencia del director, el duque de Hijar, que se encontraba en Bayona a donde había acudido como componente del séquito del infante Don Carlos, había provocado una parálisis de la que había que salir lo más pronto posible ${ }^{9}$. Los rectores de la

\footnotetext{
6 Bosch y Fustegueras, A.: El Centenario. Apuntes para la Historia de la Sociedad Económica Matritense, Imp. Manuel Tello, Madrid, 1875, pág. 108.

7 Gazeta de Madrid, 6-5-1808, pág. 436.

8 Fernández García, A.: «La sociedad madrileña de 1808», Revista de Historia Militar, extr., (2004), págs. 37-39.

${ }^{9}$ El cargo de subdirector se encontraba vacante. El duque de Híjar había pasado a ser director tras la renuncia de Godoy. Tras una nueva elección, se designó al duque de Medinaceli que no aceptó. ARSEM: A/110/33, Juntas de 19-12-1807 a 6-2-1808.
} 
Sociedad Matritense reaccionaron rápidamente ante la nueva coyuntura política para no quedarse fuera de juego. Con este propósito decidieron crear una comisión a la que encargaron visitar y rendir respetos a quien actuaba como la máxima autoridad del país en la práctica. Sin embargo, la visita no llegó a realizarse debido a que las demoras y las excusas impidieron finalmente su cumplimiento, ya que Murat, enfermo, abandonó Madrid. A pesar de todo, a petición suya, se le remitieron seis ejemplares del Informe sobre la ley agraria de Jovellanos, pues "este Cuerpo patriotico (...) está pronto á cumplir sus preceptos » ${ }^{10}$.

Posteriormente, la Matritense alegará que se vio obligada al nombramiento de esta comisión por culpa de la actuación del director del Colegio de Sordomudos que había visitado al gran duque de Berg sin autorización de la institución. Con su comportamiento la había comprometido, sin embargo, la comisión nombrada oficialmente había actuado correctamente al retraerse a la hora de homenajear al invasor, ya que «no tuvo efecto á causa de la (...) estudiada dilacion que dio la Sociedad á este ásunto para que no se verificase». Así se justificaba en agosto de 1808 una decisión que no pudo llevarse a cabo por falta de tiempo. Esta explicación de una calculada ambigüedad evitaba, de cara a los propios socios, los reproches que pudieran surgir por la actitud colaboracionista de los meses anteriores. No fueron los únicos, otros organismos gubernativos e instituciones científicas tuvieron que dar cuenta de su conducta de cara a la opinión pública ${ }^{11}$.

Una vez Madrid fue abandonado por los franceses, tras la batalla de Bailén, a principios de agosto de 1808, el duque de Híjar, que había vuelto a la capital con José Bonaparte, enseguida volvió a presidir las juntas de la Matritense. Sus miembros, conscientes de las actuaciones realizadas ante las autoridades galas, tomaron una serie de medidas encaminadas a demostrar el "patriotismo» de la institución. El 13 de agosto de 1808 decidieron borrar los acuerdos aprobados las semanas anteriores en cumplimiento del Auto publicado por el Consejo de Castilla dos días antes en el que se anulaban todos los actos ejecutados por el «gobierno intruso" por considerarse nulos de pleno derecho por la ilegitimidad y violencia con que las autoridades francesas habían procedido. En este caso se encontraban, según los miembros de la Sociedad Económica, el nombramiento de la comisión que debía cumplimentar al Lugarteniente General del Reino, ya aludida, y el envío de los ejemplares del Informe sobre la ley agraria ${ }^{12}$.

También aprovecharán para alinearse a favor de la Junta Central, tras la recepción de una Real Orden de 7 de noviembre de 1808. En ella, Pedro Cevallos, primer secretario de Estado, desde Aranjuez, después de calificar a la Sociedad como "cuerpo tan caracterizado por el verdadero patriotismo", le instaba a que presentase los planes que considerara más oportunos para mejorar la agricultura

10 ARSEM: Idem, Juntas de 21-5-1808 a 18-6-1808.

11 ARSEM: Idem, Junta de 13-8-1808.

12 Estos dos acuerdos aparecen tachados en las actas. ARSEM: Idem, Juntas de 21-5-1808, 28-51808 y $13-8-1808$. 
del país. El escrito, todo un alegato a favor del reformismo ilustrado, constituía una declaración de intenciones de la Junta Central a favor de la continuidad del programa de gobierno de Fernando VII, a pesar de su ausencia. En este sentido, aprovechaba la ocasión para recordar que el monarca en los pocos días de su reinado efectivo había dictado algunas disposiciones para favorecer la agricultura con el deseo de lograr una reputación de monarca ilustrado ${ }^{13}$. En cumplimiento de la petición de las autoridades de Aranjuez, el duque de Híjar nombró una comisión muy numerosa, cuya primera tarea consistiría en responder al secretario de Estado agradeciéndole que hubiese recurrido a la institución para elaborar un plan de reforma de la agricultura. Los socios estaban esperanzados con las primeras actuaciones de la Junta Central y confiaban en que el nuevo gobierno acometiese la tarea de revitalizar las sociedades económicas. Sin embargo, a pesar de los buenos propósitos, no hay constancia de que la comisión llegara a reunirse. Tampoco pudieron celebrarse las elecciones anuales, previstas para el día 10 de diciembre. No dio tiempo ya que la proximidad del ejército napoleónico produjo nuevamente la confusión entre los miembros de la institución ${ }^{14}$.

La derrota de Somosierra abrió a los franceses el camino hacia Madrid durante los primeros días del mes de diciembre, cuya capitulación se produjo el día 4. La conquista de la capital sirvió para que se definiesen políticamente muchos de los que hasta entonces se habían mostrado indecisos. Los que habían vinculado su suerte a José Bonaparte volvieron. Otros, ante la perspectiva de someterse al dominio francés, decidieron huir, ya que estaban resueltamente alineados con el bando patriótico. Entre ellos, el director de la Matritense, el duque de Híjar, de quien no se vuelven a tener noticias hasta finales de 1813. Algunos fueron hechos prisioneros, acusados de traidores y conducidos a Francia por sus responsabilidades en los sucesos precedentes. Únicamente los no comprometidos políticamente y aquellos que carecían de recursos económicos o de lugar donde refugiarse, se quedaron, resignándose al invasor ${ }^{15}$.

Algunos de los socios que permanecieron en la ciudad decidieron continuar la obra emprendida por la Sociedad Económica Matritense a pesar de las dificultades a las que tendrían que hacer frente. El panorama no se presentaba nada halagüeño, dadas las circunstancias. Los miembros de la Junta de Gobierno del Colegio de Sordomudos se mostraron especialmente activos, pues la gestión y supervivencia de este centro se había convertido en el asunto de mayor prioridad. No obstante, la falta de medios tanto humanos como económicos obligó a restringir algunas de sus actividades ${ }^{16}$.

13 ARSEM: Idem, Junta de 12-11-1808.

14 ARSEM: Idem, Junta de 26-11-1808.

15 TORENO, conde de: Historia del levantamiento, guerra y revolución de España, Tomo II, Ed. Ferni, Ginebra, 1974, págs. 200-202.

16 Demerson, J.: «La Sociedad Económica Matritense en tiempo de José l», Boletín de la Real Sociedad Vascongada de los Amigos del País, 25, (1969), pág. 44. 


\section{DE LA NEUTRALIDAD POLÍTICA AL CONTROL DE LOS AFRANCESADOS}

Los habitantes de Madrid acabaron el año de 1808 con la ciudad ocupada por las tropas francesas. El día 22 de enero de 1809, José I entraba en la capital, después de haber sido repuesto en el trono por su hermano, reorganizando su servidumbre con aquellos que no le habían abandonado. Asimismo, los ministros que le habían seguido desde agosto fueron confirmados en sus cargos. Comenzaba la segunda etapa de su reinado que se prolongaría hasta principios de $1813^{17}$.

Las juntas de la Matritense, interrumpidas el 26 de noviembre de 1808, se reanudaron el 21 de enero de 1809. La huida de Madrid de muchos de sus habitantes había dejado a la Sociedad sin sus cuadros directivos. Bernardo Iriarte, el socio más antiguo residente en la capital, actuó como director accidental. El propósito de esta junta respondía a la urgencia en aprobar las autorizaciones de los pagos necesarios para la supervivencia del Colegio de Sordomudos pues la falta de toma de decisiones estaba afectando seriamente su funcionamiento. Además, los socios tenían que resolver las diferentes cuestiones que se habían ido acumulando a lo largo de los dos últimos meses.

La Matritense tuvo noticias del nuevo gobierno incluso antes de la entrada oficial del rey José en la capital. Para conocer su estado el ministro del Interior, Manuel Romero, se dirigió a la corporación por medio de la Real Orden de 6 de enero de 1809 requiriendo una información precisa sobre los establecimientos científicos, de educación y beneficencia que gestionaba. Aprovechando la primera reunión, los socios redactaron rápidamente el informe con la intención de que el nuevo gobierno se mostrase favorable a los fines de la institución y mantuviese la financiación de sus centros ${ }^{18}$.

Por otra parte, la corporación no pudo librarse de los rigores que impuso la política josefina desde el primer momento. Una de las medidas del nuevo régimen para organizar la Administración pública, con vistas a la depuración de los que no fueran adictos al nuevo régimen, consistió en la exigencia de jurar fidelidad al rey tanto a los nuevos nombramientos como a los antiguos funcionarios que quisieran continuar en sus destinos. Con esta disposición los afrancesados intentaban presionar a los empleados públicos para que vinculasen su suerte a la nueva dinastía. El Decreto 16 de febrero de 1809 establecía la manera de efectuar esta obligación y añadía una amenaza directa sobre el que incumpliese la orden, advirtiendo que la negativa se consideraría como dimisión de su empleo. Esta medida se amplió con otro decreto publicado en mayo y dirigido contra los ausentes,

17 Mercader Riba, J.: José Bonaparte, rey de España (1808-1813). Historia externa del reinado, CSIC, Madrid, 1971, págs. 80 y 90-93.

18 ARSEM: A/110/36, Libro de Actas de las Juntas de la Sociedad (1809-junio 1812), Junta de 21-11809. 
a los que se intimidaba con el secuestro de sus bienes si no se restituían a sus antiguos destinos ${ }^{19}$.

El Decreto fue enviado a la Matritense desde el ministerio de Interior. La institución siempre se había considerado a sí misma como una corporación autónoma del gobierno, a pesar de financiarse en gran medida con fondos públicos y de que la mayoría de sus directores habían formado parte de los equipos gubernamentales en la época de Carlos IV. Los socios se daban cuenta de que el juramento de fidelidad podría conllevar consecuencias futuras no deseadas para la independencia de la institución. El problema residía en buscar una salida airosa a la situación en la que se encontraban, evitando el compromiso de la mejor manera posible. Nunca, hasta entonces, los rectores de la corporación habían tenido que someterse a un juramento. Únicamente el nombramiento de director se supeditaba a la aprobación real, pero más como un formulismo de acatamiento de la voluntad soberana pues en ninguna ocasión anterior el rey había vetado la elección, realizada libremente entre los socios. El día fijado, 18 de marzo, se procedió a realizar el acto de juramento. Los asistentes a la ceremonia decidieron que debía requerirse únicamente a aquellos que percibían un salario por parte de la institución (el maestro y resto de empleados del Colegio de Sordomudos, los oficiales de la secretaría y el portero de la Sociedad). Todos ellos cumplieron la obligación impuesta y, sin embargo, ningún miembro del equipo directivo lo ejecutó ${ }^{20}$.

Resuelto el trámite, durante el primer semestre del año de 1809 la Sociedad siguió reuniéndose tranquilamente sin ser molestada en los locales del Colegio de Sordomudos, olvidada de las autoridades. En este periodo se dedicaron a atender casi exclusivamente a los asuntos de dicho centro, pues las secciones de las que se componía la institución (Agricultura, Industria y Artes y Oficios), en las que se desarrollaban los trabajos de los socios, habían interrumpido sus reuniones por falta de asistentes ${ }^{21}$.

Desde el principio de la dominación napoleónica el estado de las finanzas fue motivo constante de preocupación de la Sociedad Matritense. La tenacidad que demostraron los socios con la decisión de conservar abierto el Colegio de Sordomudos les obligó a dedicar más tiempo del debido, buscando medios para su subsistencia $^{22}$. Las reiteradas alusiones a las deudas a las que tenían que hacer frente constatan una penuria económica que, a la larga, condicionó las relaciones

19 Decreto de 16-2-1809 y Decreto de 2-5-1809 en Prontuario de las Leyes y Decretos del Rey Nuestro señor Don José Napoleon I, Tomo I, Imp. Real, Madrid, 1810, págs. 107-109 y 178.

20 Tampoco lo realizó el maestro de la Escuela de Taquigrafía, Francisco de Paula Martí, que alegó que ya lo había hecho en dos ocasiones, una como vecino de Madrid y otra como miembro de la Real Academia de Bellas Artes de San Fernando. ARSEM: A/110/36, Junta de 18-3-1809.

21 Demerson, J.: Op. cit., pág. 46.

22 La Escuela de Taquigrafía había cerrado por la destrucción sufrida en los combates previos a la capitulación de Madrid en diciembre de 1808, véase NEGRín FAJARDO, O.: «La primera cátedra española de Taquigrafía: la Real Escuela de Taquigrafía de la Sociedad Económica Matritense (1802-1808)», Revista de Ciencias de la Educación, 101, (1980), págs. 9-30. 
con el gobierno. Las continuas reclamaciones de los acreedores provocaban un derroche de esfuerzos en asuntos que en otra coyuntura política y económica habrían pasado inadvertidos. Algunos de sus miembros fueron conscientes en todo momento de que la ruina de la institución era el resultado directo de haber abarcado en el pasado más de lo que podía asumir con sus propios medios, acaparando competencias que debían ser asumidas por el Estado, lo cual había conducido a la difícil situación en la que se veían inmersos. En una de las sesiones, el censor reflexionaba sobre el estado de la institución, dirigiéndose a sus compañeros: "Consideradnos combertidos de Maestros del bien por medio de la ilustracion, en solicitadores de caudales para fomentarle; y al punto deducireis conmigo que del trastorno de las nobles y generosas funciones, que nos devian caracterizar, provienen las necesidades á que nos sujetamos, (...) cuidamos de establecimientos que estan confiados á nosotros (...) ¿Pero trabajamos de difundir las luces? ¿llustramos la nacion con nuestras tareas? Seguimos un sistema de adelantamiento? Nada» ${ }^{23}$. Poco a poco la insuficiencia económica fue degenerando hasta casi la quiebra de la institución, ya que a la dificil situación financiera que arrastraba desde tiempo atrás se unieron las dificultades del régimen josefino para asumir las obligaciones en materia de educación y beneficencia. Además, la voracidad fiscal del propio gobierno afrancesado contribuyó por su parte a que las finanzas de la Sociedad acabaran en el desastre antes de lo que los socios podían prever ${ }^{24}$.

En el verano de 1809, Madrid sufrió otra crisis de nerviosismo. Desde principios de julio la capital se hallaba bastante agitada por los rumores que se habían propagado con las noticias de la aproximación del ejercito inglés al mando de Wellington. El día 23, el rey francés partía de la ciudad, acompañado de algunos de sus colaboradores más estrechos que le siguieron aterrorizados, lo que se interpretó como una huida. Después de conocer los resultados indecisos de la batalla de Talavera, muchos de los habitantes de Madrid se sintieron decepcionados. Pero la situación de la capital no quedó asegurada hasta el 11 de agosto cuando, una vez replegados los británicos hacia Portugal, los restos de los ejércitos españoles fueron vencidos en Almonacid (Toledo). El 14 de agosto José regresó a Madrid y en los días siguientes los miembros de su gobierno y administración ${ }^{25}$. A raíz de estos sucesos, el gobierno josefino tuvo clara conciencia de su impopularidad. La nobleza, el clero y muchos empleados públicos, a pesar de los juramentos de fidelidad al rey, ejecutados a principios del año, ante la posibilidad de la derrota de las fuerzas galas, habían mostrado abiertamente su oposición al régimen. Entonces, los afrancesados recurrieron a una serie de resoluciones, muchas de ellas represivas, con las que intentaban afianzar su posición. Entre ellas, el Decreto de 18

${ }^{23}$ ARSEM: Exp. 209/2.

24 En la junta de 10 de junio de 1809 el tesorero León de Galarza comunicó la incautación de los fondos que custodiaba del Montepío de Hilazas (que ascendían a 130.100 reales, repartidos en dinero en efectivo y vales reales) por parte de un comisario de Policía enviado por el ministro Pablo Arribas. Este capital constituía la única reserva de la institución. Las reclamaciones a las autoridades fueron continuas, sin que se consiguiera su recuperación. ARSEM: A/110/36, Junta de 10-6-1809.

${ }^{25}$ Mercader RibA, J.: Op. cit., pág. 116-119. 
de agosto de 1809 obligaba a que los funcionarios solicitasen individualmente, mediante petición al monarca, la confirmación en sus puestos ${ }^{26}$.

Otra vez la Sociedad se veía en la tesitura de mostrar su fidelidad al gobierno. Mediante la Orden comunicada por la segunda división del ministerio de Interior de fecha 18 de septiembre, el ministro Manuel Romero les informaba que, para el cumplimiento del decreto anterior, la institución debía exigir a sus empleados que hicieran individualmente una solicitud al rey para poder continuar en sus empleos. La Matritense decidió responder con un memorial en el que se incluiría la respuesta aportada por todos sus empleados ${ }^{27}$.

En el último cuatrimestre de 1809 comenzó el acercamiento de los afrancesados hacia la Matritense. El día 2 de septiembre acudió por primera vez a la junta semanal José Martínez de Hervás, marqués de Almenara, que se convertirá a lo largo de este periodo en una de las más activas personalidades del gobierno josefino que intentaron sacar a la Sociedad de su letargo. Después de informarse sobre el estado de la institución, a la que llevaba sin acudir mucho tiempo, puesto que en los últimos años había estado alejado de España ejerciendo diversos destinos diplomáticos, propuso que se formase una relación de las actividades de la corporación con el fin de poder requerir del gobierno la protección económica que necesitasen para desarrollar sus tareas. Un mes más tarde, estuvo más explícito en sus propuestas con el objetivo de sacudir la inercia de la corporación. En primer lugar, para intentar el florecimiento de la institución había que lograr que los socios volviesen a concurrir a las reuniones, en segundo lugar, buscar la implicación de aquellos que estaban bien situados en los puestos principales del gobierno $y$, por último, consideraba indispensable la protección del rey tanto institucional como económicamente. A tal fin, convocó a los miembros más importantes para que acudiesen a la siguiente reunión para deliberar sobre los medios para revitalizar la institución con vistas a que el rey la favoreciese ${ }^{28}$. Empezaba la estrategia de los afrancesados para prestigiar su política, sirviéndose de la corporación madrileña ${ }^{29}$.

A la sesión del 14 de octubre asistieron, además del marqués de Almenara, el conde de Cabarrús, José de Mazarredo y Manuel María Cambronero, todos ellos

26 Decreto de 18-8-1809 en Prontuario..., Tomo I, págs. 396-397.

27 El catedrático de taquigrafía, Francisco de Paula Martí, se sumó en esta ocasión, pidiendo la confirmación de su destino. Alegaba que se había visto obligado a cumplir el juramento porque llevaba 18 meses sin percibir su sueldo. ARSEM: A/110/36, Juntas de 23-9-1809 y 25-9-1809.

28 Fueron invitados: Bernardo Iriarte, José de Mazarredo, el conde de Cabarrús, Manuel Sixto Espinosa, el conde Montarco, el conde de Campo Alange, Manuel María Cambronero y Mariano Luis de Urquijo. ARSEM: Idem, Juntas de 2-9-1809, 7-10-1809 y 14-10-1809.

29 Jorge Demerson opina que «En octubre de 1809 a insinuación del Ministro del Interior, D. Manuel Romero, el rey manifiesta el deseo de que se reorganice la sociedad». En el mismo sentido se manifiesta Juan Mercader Riba que sigue al anterior. En realidad, la propuesta partió del marqués de Almenara que pretendía, por el conducto del ministro del Interior, que el soberano protegiera la institución. DEMERSON, J.: Op. cit., pág. 46 y MeRcAdeR RIBA, J.: José Bonaparte, rey de España (1808-1813). Estructura del Estado Español Bonapartista, CSIC, Madrid, 1983, pág. 439. 
destacados personajes afrancesados. Con ellos parecía que la institución podría empezar a tomar un nuevo impulso ya que se mostraron muy favorables a la idea de que recibiese el apoyo del gobierno josefino. Sus propuestas buscaban "los medios de procurar la prosperidad y engrandecimiento de este Cuerpo patriotico, manifestando el aprecio que les merece, y la consideracion en que debe ser tenido justamente por el Gobierno, y la nacion entera, tanto por la importancia de los obgetos á que atiende, quanto por el desinteresado é infatigable zelo con que se há ocupado desde sus principios en el bien general» ${ }^{30}$.

Como primera medida Cambronero debía hacer saber al ministro del Interior el deseo de los socios de que el rey protegiese a la corporación. A la vez, solicitaría del ministro una pequeña dotación para las necesidades más urgentes. Además, el conde de Cabarrús quedó encargado de buscar un local donde celebrar las reuniones, ya que desde hacía más de un año se celebraban en el Colegio de Sordomudos, lugar poco apto para las sesiones. A la semana siguiente, la visita había surtido el efecto deseado, ya que Manuel Romero había recibido con interés a los enviados de la institución y se había mostrado favorable ante sus peticiones. Por otro lado, Cabarrús cumplió su cometido con toda celeridad ya que comunicó que había encontrado un local apropiado donde efectuar las juntas. Las próximas reuniones podían celebrarse en una sala del Palacio de los Consejos, concretamente en la destinada al desaparecido de Hacienda ${ }^{31}$.

Con motivo de la concesión de la nueva sede, Almenara redactó una nota que se mandó publicar en la Gazeta para el conocimiento de los miembros de la Sociedad, instándoles a que acudiesen al nuevo local, ya que se albergaban grandes esperanzas ante su restablecimiento, puesto que «todo socio irá a multiplicar sus esfuerzos para llevar dignamente el título de Amigo del País, el más noble y el más distinguido de cuántos puede ambicionar el más elevado ciudadano» ${ }^{32}$.

Después del anuncio, como había previsto, la reunión del 4 de noviembre contó con una nutrida afluencia. En ella, los socios trataron la manera de conseguir la ayuda que necesitaban para mantener los establecimientos de educación y beneficencia. Para ello redactarían una solicitud para el rey que debía enviarse a José de Mazarredo, el ministro de Marina, que se ofreció para interceder por la corporación ante el ministro Romero y el monarca. A los pocos días, comunicaba que el gobierno haría todo lo posible para auxiliar provisionalmente a la Sociedad ${ }^{33}$.

La aparición de personas influyentes por la Matritense parecía que empezaba a resolver los problemas. Otro motivo de esperanza fue el cambio del ministro de

30 ARSEM: A/110/36, Junta de 14-10-1809.

31 ARSEM: Idem, Junta de 21-10-1809.

32 Gazeta de Madrid, 3-11-1809, pág. 1348.

33 Entre los asistentes: José de Mazarredo, el conde de Cabarrús, el marqués de Almenara, el conde de Montarco, Manuel María Cambronero y Manuel de las Heras. En el año de 1809 las reuniones registraron una concurrencia entre 5 (mínimo necesario para constituir la junta) y 12 personas como máximo, excepto en esta sesión que se presentaron 28 socios. ARSEM: A/110/36, Juntas de 4-11-1809 y 11-11-1809. 
Interior. El marqués de Almenara había sido nombrado para esta cartera en sustitución de Manuel Romero que pasaba a ejercer la de Justicia. Hasta entonces, el ministerio se había mostrado bastante pasivo ante las solicitudes de la corporación, limitándose a recabar informes sobre sus necesidades y a dar buenas palabras pero sin llegar a arbitrar una solución concreta a las solicitudes que le habían planteado ${ }^{34}$.

A finales de 1809 la institución podía darse por satisfecha ya que contaba entre sus miembros con cinco ministros en el gobierno de José Bonaparte (el marqués de Almenara, José de Mazarredo, el conde de Cabarrús, Mariano Luis de Urquijo y el conde de Campo Alange). Al mismo tiempo, otros socios importantes figuraban en diversos organismos de la administración afrancesada. Los tres primeros se habían mostrado especialmente sensibles a las necesidades de la corporación. Su implicación favoreció, sin duda, la concesión de financiación a favor de la Sociedad. En este sentido, el conde de Cabarrús, por ausencia del nuevo titular de Interior, comunicó a la institución la Real Orden de 16 de enero de 1810 en la que se aprobaba por el rey una asignación mensual de 1.500 reales para gastos de secretaría y juntas. Mientras, el mismo conde incitaba a que se elaborase el plan general de restablecimiento, que consideraba fundamental para que comenzasen a resolverse los problemas de la decadencia de la corporación ${ }^{35}$.

Sin embargo, la alegría duraría poco tiempo. El 27 de abril de 1810 fallecía Cabarrús en Sevilla. A esto se sumó la ausencia del marqués de Almenara, su más decidido impulsor. José Martínez de Hervás había sido enviado a París a principios de agosto con la misión de negociar con Napoleón sobre el asunto de la segregación de las provincias lindantes con Francia. En Madrid, supliendo su puesto se había quedado el antiguo ministro Manuel Romero, que tanto despego había mostrado por la Matritense y que no tardó en suprimir la asignación mensual aprobada por los anteriores ${ }^{36}$.

Durante el año de 1809 las tareas propias de la institución habían quedado relegadas a un segundo término ante los problemas financieros. Al dejar de funcionar las clases, los trabajos fueron abandonándose poco a poco. Sólo a finales de dicho año parece que se animaron los socios a retomar algunas tareas que continuaron durante el siguiente. En el primer año se limitaron a realizar varios informes. Uno sobre un Plan de Escuelas de Agricultura de Antonio Sandalio de Arias, que posteriormente mejoró y volvió a presentar a la Sociedad en 1811. Otro consistió en la revisión de una máquina de hacer zapatos inventada por el ebanista Luis Negro

34 El conde de Laforest, embajador de Francia en Madrid, se hace eco del restablecimiento de la Sociedad. Juan Mercader Riba califica este acontecimiento, junto a otras disposiciones tomadas, que «José Napoleón I y sus ministros se dispusieron a gobernar una España para ellos en trance de mutaciones profundas». Mercader RiBA, J.: José Bonaparte... Historia Externa..., págs. 126-127.

35 ARSEM: A/110/36, Juntas de 13-1-1810, 27-1-1810 y 10-2-1810.

36 La Sociedad reclamó insistentemente la subvención concedida, sin conseguir más que cantidades esporádicas, 1.197 reales en octubre de 1810, otros 1.197 en noviembre de 1810 y 1.000 en febrero de 1811. ARSEM: Idem, Juntas de 18-8-1810, 25-8-1810, 8-12-1810 y 23-2-1811. 
que mereció la concesión de una medalla por la institución. Por su interés se mandó publicar una reseña en la Gazeta. En el año de 1810 realizaron un dictamen sobre una máquina para moler trigo cuyos autores solicitaban el privilegio de patente y respondieron a una solicitud para instalar una fábrica de botones de ballena en el Montepío de Hilazas. Por otra parte, el socio Antonio Regás ofreció para la colección de máquinas de la Sociedad un torno de hilar seda premiado por la Junta de Comercio y Moneda, otro para hilar lino y una sierra de cuatro hilos que estaba construyendo ${ }^{37}$.

A pesar de esta incipiente vuelta a la normalidad, surgida del interés de los afrancesados hacia la Matritense, la confianza puesta en el gobierno josefino se topaba de bruces con la cruda realidad. A mediados de agosto de 1810, la situación del Colegio de Sordomudos era insostenible. Las deudas alcanzaban más de 20.000 reales, por lo que no quedaba otra opción que proceder a su clausura. Con la intención de evitar esta medida definitiva surgieron algunas soluciones provisionales ${ }^{38}$. Reduciendo los gastos al máximo, bastaría con 400 reales semanales para mantener el Colegio durante unos meses. Incluso estaban dispuestos a aceptar el dinero que recibiesen del gobierno en concepto de préstamo. Ante la imposibilidad de resolver el problema, los socios pusieron en marcha todos los resortes a su alcance. Acudieron al ministro Mazarredo para informarle de su estado y a Manuel Romero para hacerle la entrega formal del mismo, con el fin de persuadirle para que suministrase alguna cantidad. Algo se debió conmover el frío corazón del ministro, puesto que después de mucho insistir, puso a su disposición unos 2.000 reales, procedentes de las colectas de algunas parroquias de Madrid. Con este dinero se prolongaba la agonía un poco más. El secretario de la Junta de Gobierno del Colegio dimitió superado por la desastrosa situación ${ }^{39}$.

\section{LA DIRECCIÓN DEL MARQUÉS DE ALMENARA}

Pese a todos estos reveses, a los socios les daba la sensación de que algo estaba cambiando, aunque muy lentamente y confiaban que los frecuentes contactos con las autoridades josefinas podrían proporcionar a la corporación algún resultado favorable. Comprometidos ya de forma más o menos voluntaria con los afrancesados, pensaron que era un buen momento para celebrar las elecciones, que no se habían llevado a cabo desde finales de 1807. La situación de interinidad había durado demasiado. Así, el día 27 de noviembre de 1810 se realizaron las votaciones. Como era de esperar, salieron elegidos dos ilustres afrancesados: director, el marqués de Almenara y subdirector, José de Mazarredo. Los designados acepta-

37 ARSEM: Idem, Juntas de 9-9-1809 a 19-5-1810.

38 Sobre el Colegio de Sordomudos en estos años, véase PLANN, S.: «Roberto Francisco Prádez: sordo, primer profesor de sordos», en Revista Complutense de Educación, vol. 3, 1-2, (1992), págs. 237262.

39 ARSEM: A/110/36, Juntas de 13-10-1810 a 29-12-1810. 
ron el nombramiento y, a continuación, se hizo la correspondiente representación al rey para que aprobase la elección del primero ${ }^{40}$.

La nueva dirección dio un nuevo impulso que abría un nuevo periodo de esperanza. Los dos ministros, ayudados por sus partidarios dentro de la corporación, lograron imbuir en el resto de miembros un nuevo optimismo con el que afrontar la revitalización de la Matritense. El hecho de que asistiesen asiduamente a las reuniones servía de incentivo para que el resto de socios trabajasen con mayor aliciente, al mismo tiempo que ejercían el control necesario para que las propuestas siguieran el camino previsto con el propósito de que sirviesen directamente a los intereses del gobierno. Sus objetivos para la renovación de la corporación se concretaban en dos aspectos importantes: por una parte, acometer de forma decidida la reforma de las disposiciones que afectaban a su organización interna y, por otra, estimular la reanudación de las actividades que se habían visto interrumpidas por causa de la guerra ${ }^{41}$.

El primer objetivo, el plan de modificación del gobierno interno de la Matritense, abarcaba tres cuestiones que debían recibir un nuevo tratamiento: la admisión de socios, la elaboración de un plan financiero y la reforma de los Estatutos. Los tres asuntos requerían que el régimen josefino se implicase activamente en su desarrollo, puesto que necesitaban su autorización en última instancia. Sin embargo, sólo la primera cuestión se acometió con éxito. Las dos restantes quedaron sin concluir puesto que la penuria financiera de la Hacienda estatal y la excesiva lentitud para acometer las transformaciones en profundidad truncaron los buenos propósitos.

En primer lugar, la Sociedad presentó al monarca un proyecto para la incorporación de nuevos miembros. La proposición partió del censor que había observado las dificultades que ofrecía el vigente Reglamento de admisión de 1802. Esta disposición había conducido a que las solicitudes de nuevos componentes escasearan, porque exigían «requisitos y solemnidades que para nada conducen sino $\mathrm{p}^{\mathrm{a}}$. retraer á ciertas personas, y dificultar el pronto despacho de otras». Así, en la junta de 15 de diciembre de 1810 aprobaron una nueva regulación que eliminaba la exigencia de condiciones superfluas de los candidatos y simplificaba los trámites internos $^{42}$. El Decreto de 24 de diciembre de 1810 de admisión de socios en la Matritense aportaba algunas novedades respecto al proyecto remitido al ministerio de Interior en el sentido de facilitar la entrada de todos los interesados que lo solicitasen. Se evitaba cualquier alusión a las características del candidato, estipulando

40 ARSEM: Idem, Junta de 27-11-1810.

41 Años después, en un escrito publicado para defenderse de su etapa al servicio de José Bonaparte, el marqués de Almenara se refiere a su interés por la Sociedad Económica: «Antes de ser ministro, me ocupé de restablecer la Sociedad y de hacer algunos servicios» y elogia también la labor realizada por Mazarredo y Cabarrús. ALMENARA, marqués de: El marqués de Almenara a su defensor y a sus jueces, Imp. del Censor, Madrid, 1820, págs. 37-38.

42 ARSEM: Exp. 209/21. 
como única condición que fuera útil para la institución La votación para el ingreso se haría a continuación de la lectura por parte del secretario del memorial del candidato en el caso de que fuera conocido por la mayor parte de los asistentes y si no ocurría así, se diferiría para la siguiente sesión ${ }^{43}$.

En los primeros meses del año de 1811, nada más ponerse en vigor el nuevo Reglamento, se incrementaron las solicitudes de incorporación a la Matritense. Mientras que en los años anteriores las peticiones habían sido muy limitadas (una en 1808, dos en 1809 y tres en 1810), en cambio en el año de 1811 se registraron 28 admisiones, concentradas especialmente en los tres primeros meses del año, que ascendieron a 25. De estos últimos, 10 ocupaban puestos en el ministerio de Interior y la mayoría de los restantes, diferentes cargos de responsabilidad en la administración josefina. La amistad, la influencia o, incluso, la presión del marqués de Almenara no estaba muy lejos de muchas de estas instancias. Algunos de ellos como Juan Meléndez Valdés, Vicente González Arnao, Francisco Antonio Zea, José Marchena, Cristóbal Cladera y Ramón de Salas unían a su conexión con el régimen afrancesado el prestigio de su labor científica o intelectual, ya desarrollada antes de la invasión napoleónica. Varios de los nuevos socios se tomaron en serio su pertenencia a la Matritense y en estos años contribuyeron activamente para sacar a la corporación de su parálisis, como en el caso de los tres primeros citados. Sin embargo, otros nunca llegaron a comprometerse seriamente con sus actividades. Además, entre estos personajes también se deslizan otros que, por estar menos comprometidos políticamente con el régimen josefino, posteriormente en el reinado de Fernando VII, colaboraron asiduamente en las tareas de la Sociedad (entre ellos, el botánico Simón de Rojas Clemente, el veterinario Agustín Pascual y el arabista José Antonio Conde). Después de este breve periodo de auge, las incorporaciones volverán a la tónica habitual de estos años caracterizados por su escasez. En el año de 1812 únicamente hubo tres y a principios de 1813, una única solicitud. Sin embargo, hay que destacar que el 30 de mayo de 1812, pasó a formar parte de la institución el propio rey José, tras la audiencia que concedió a una representación de la misma. Fue incluido en el Catálogo de socios como protector, distinción que se reservaba para los reyes e infantes de España y que la habían ostentado con anterioridad únicamente miembros de la familia Borbón ${ }^{44}$.

En segundo lugar, se elaboró un nuevo plan general de gastos y obligaciones de la Sociedad. El conde de Cabarrús, el marqués de Almenara y José de Mazarredo ya habían tratado de enterarse directamente de las necesidades financieras hacía más de un año y también en otras ocasiones había sido requerida la misma información por parte de diversos organismos del régimen afrancesado desde principios de 1809. El último proyecto se aprobó en la junta de 26 de enero de 1811 y a continuación fue enviado a todas las autoridades que lo habían solicitado. Las dificultades financieras de la Hacienda josefina impidieron que pudiera llevar-

43 ARSEM: A/110/36, Junta de 5-1-1811.

44 Algunos de los socios admitidos durante estos años en Demerson, J.: Op. cit., pág. 47. 
se a cabo en todos sus términos. Con gran ambición, el informe recorría la historia de los diferentes establecimientos educativos y de beneficencia a cargo de la institución desde sus inicios y las necesidades de cada uno de estos centros ${ }^{45}$.

En tercer lugar, quedaba el tema de la reforma de los estatutos. El proyecto de modificación de la constitución interna de la Sociedad había sido encargado al censor Tiburcio Hernández y a Domingo Agüero en la junta de 10 de febrero de 1810. Un año más tarde presentaron su propuesta, en la que intentaban atajar los principales males que habían causado la decadencia de la institución. Estas causas configuraban un círculo vicioso del que había que intentar salir cuanto antes. La principal consistía en la carencia de fondos propios con los que llevar a cabo con éxito todas las actividades. La necesidad de subsistir con el apoyo oficial provocaba a su vez la excesiva dependencia del gobierno. Esta última incidía en la falta de libertad en las reuniones y, por consiguiente, en la inasistencia de los socios, con lo cual la ausencia de una autofinanciación suficiente obligaba a recurrir a las subvenciones públicas. Afirmaba el censor que los motivos de la decadencia de la institución eran «el cuidado que se ponia [desde hacía] algun tiempo para impedir toda reunion" y «la desconfianza que produce la triste situacion indicada». Respecto a la falta de independencia, creía que «Por querer ser mas util [la Sociedad], se fue labrando cierta dependencia que de eslabon en eslabon la llebó a subsistir precariam ${ }^{\text {te }}$., y aunque tubiese el placer de haber socorrido con liveralidad generosa á varias personas y establecimientos, por otra parte se separó progresivamente de sus obgetos, y teniendo que sucumbir á la alternativa de los fondos publicos, quando estos la faltaron, quedó inerte, y reducida á censora de travajos agenos, sin ocuparse en ninguno propio " ${ }^{46}$.

A continuación se procedió a nombrar una comisión que revisase la propuesta y redactase el articulado. Sus trabajos se prolongaron prácticamente durante todo el año de 1811 y en ella analizaron concienzudamente los diferentes aspectos que debían incluirse en la nueva regulación. El proyecto se presentó a principios de 1812 a la junta de dirección que empezó a discutirlos con vistas a su aprobación definitiva. La inestabilidad política que sufrió el régimen afrancesado durante dicho año truncó la posibilidad de una reforma en la que se invirtió gran cantidad de tiempo y que se acometió con gran seriedad por parte de los que participaron en ella ${ }^{47}$.

En resumen, el proyecto de la comisión de Estatutos se fundamentaba en una reorganización en la que desaparecían como objetivos a desarrollar por la Matritense todos aquellos que no se vincularan estrictamente con el fomento económico. Las funciones de la corporación se modernizaban en dos direcciones. Por

45 Durante estos años los requerimientos de información procedieron del ministerio de Interior (bajo sus titulares Romero y Almenara), de Francisco Amorós, del conde de Guzmán y del prefecto de la provincia de Madrid. ARSEM: A/110/36, Juntas de 17-11-1810 a 26-1-1811.

46 ARSEM: Exp. 212/1.

47 La comisión estaba presidida por el subdirector, José de Mazarredo. ARSEM: A/110/36, Junta de Dirección de 5-1-1811. 
una parte, la actividad considerada como propia que consistía en el desarrollo de una labor fundamentalmente intelectual o científica, basada en el trabajo de investigación, experimentación y divulgación de los conocimientos e innovaciones relacionadas con las materias económicas, especialmente en el campo de la Economía política y los sectores agrícola, industrial y comercial. En este aspecto se dedicarían a la elaboración de diccionarios económicos, la publicación de cartillas y la convocatoria de unos premios anuales previstos para el estímulo del desarrollo económico del país. Por otra parte, los trabajos de asesoramiento a otras instituciones que lo requiriesen, no exclusivamente al gobierno, sino que se ampliaba a municipios e, incluso, a los particulares. Estas tareas se concretaban en la redacción de informes, el examen y prueba de inventos, la realización de experiencias en el campo científico o económico y la resolución de los expedientes enviados para su dictamen ${ }^{48}$. El resto de labores que se habían incorporado sucesivamente, especialmente en el campo de la enseñanza y en el asistencial, se desechaban puesto que consideraban que estos establecimientos debían depender de manera exclusiva del gobierno que estaba obligado a dotarlos adecuadamente y encargarse directamente de su gestión sin intermediarios. Estas actividades habían provocado el desastre financiero en el que estaban inmersos. La propia experiencia les había llevado a la conclusión de que su sostenimiento era inviable en las actuales circunstancias, ya que los buenos propósitos no resolvían por si solos sus necesidades. La influencia política francesa de un Estado fuertemente centralizado con competencias bien definidas también flotaba en el ambiente. Ante la tesitura de perder protagonismo político, al dejar de ser un interlocutor necesario con el gobierno en estos asuntos, los miembros de la comisión de reforma de los Estatutos, conscientes de sus propias limitaciones económicas, se habían convencido de que, para evitar la ruina de la institución y su falta de independencia, debían desvincularse completamente de las ocupaciones no comprendidas estrictamente en su objeto social.

No obstante, a pesar de evitar la dependencia financiera del Estado mediante la restricción de las actividades, la reforma no prescindía totalmente de los fondos públicos. El gobierno debía proporcionar a la corporación unas subvenciones regulares y proporcionadas para poder realizar sus objetivos adecuadamente, ya que, según el proyecto, la Sociedad Económica constituía una especie de órgano asesor dedicado fundamentalmente al progreso económico de la nación y, por tanto, un fiel colaborador del poder establecido, con sus mismos intereses para la consecución de dicho fin. Una asignación fija que no estuviera expuesta a los vaivenes políticos y que evitase el derroche de esfuerzos en cuestiones no relacionadas con su objeto específico. Además, las contribuciones de los socios pasaban a ser voluntarias. La mayoría de sus miembros no las satisfacían y no se consideraba apropiado su reclamación que sólo conducía a la disminución de socios ${ }^{49}$.

48 ARSEM: Exp. 212/1.

49 ARSEM: Ibidem. 
Concluidas las reuniones de la comisión de reforma de estatutos, Martín Fernández de Navarrete se encargó de la redacción definitiva de su articulado, mientras José Garriga y Tiburcio Hernández elaboraban una introducción que justificara la idoneidad del proyecto de modificación. En la junta el 18 de enero de 1812 , presentaron su informe y en las semanas posteriores los socios discutieron uno por uno los artículos de la nueva regulación hasta que en marzo de 1812 interrumpieron su revisión pues el asunto de la visita al rey José acaparó el interés de las reuniones.

En estos primeros meses de reorganización, la Sociedad desplegó una gran energía en todas sus tareas, ya que intentó por todos los medios recuperar las ocupaciones que se habían dejado abandonadas en los años anteriores. Si la Matritense quería volver a convertirse en una institución prestigiosa, como quería el gobierno, era necesario de cara a la opinión pública mostrar una actividad renovada que propiciase la afluencia de socios y estimular un ambiente favorable para la modernización económica, como había ocurrido en el último tercio del siglo XVIII. Por consiguiente, ordenaron los asuntos pendientes, requiriendo a los socios la información precisa sobre los encargos que se habían dejado a medias y buscaron los expedientes de los que se tenía conocimiento que estaban trabajando antes de la invasión francesa. Para ello fue preciso recabar noticias sobre los bienes confiscados de los socios que habían huido para localizar los papeles de la institución. De esta manera, pudo plantearse a continuación el restablecimiento de las diferentes clases, que habían dejado de reunirse desde finales de 1808.

La comisión interina de Agricultura empezó a funcionar en marzo de 1811. Para su restablecimiento, convocaron a todos los adscritos a la antigua clase que permanecían en Madrid. Una vez constituida se nombró un presidente, Casimiro Gómez Ortega, el vocal más antiguo, y un secretario ${ }^{50}$. La primera sesión se celebró el 20 de marzo y se reunió semanalmente prácticamente sin interrupciones durante año y medio hasta el 16 de septiembre de 1812, fecha en la que se suspendieron sus juntas. La asistencia osciló entre cinco y trece miembros. Casi todos sus componentes concurrieron alguna vez y realizaron algún trabajo en su seno. La principal ocupación, en esta etapa, consistió en la redacción de los primeros capítulos de la edición comentada de la obra Agricultura General de Gabriel Alonso Herrera, tarea que se prolongó hasta 1818 cuando finalmente fue publicada en cuatro tomos ${ }^{51}$. Este trabajo gozaba de un gran interés, según los miembros de la clase de Agricultura, ya que la obra de este célebre agrónomo español del siglo XVI, publicada por primera vez en 1513, había sido recomendada por Jovellanos en el Informe sobre la ley agraria por su utilidad para la divulgación de los conocimientos agrícolas. El objetivo final de la revisión de la obra buscaba

50 La secretaría recayó en Ramon Robert hasta el 28-5-1811 que fue nombrado Claudio Boutelou. ARSEM: A/110/36, Juntas de 2-3-1811 y 16-3-1811.

51 Herrera, G. A. de: Agricultura General, corregida de la primera edicion de 1513 y adicionada por la Real Sociedad Matritense, 4 tomos, Imp. Real, Madrid, 1818-1819. 
su impresión según la edición original, quitando los añadidos posteriores y actualizándola con la ciencia del momento ${ }^{52}$. Además, la sección se dedicó a otras actividades como la revisión de memorias pendientes, la lectura de informes realizados por algunos socios y el examen de diversas obras de agricultura extranjeras con vistas a su traducción ${ }^{53}$.

La comisión interina de Artes y Oficios había sido nombrada en febrero de 1811. Tenía menos componentes que la de agricultura, pese a que agrupaba a los antiguos socios adscritos a las dos clases de Industria y de Artes y Oficios, a las que sustituyó. Esta sección tuvo una vida más precaria, puesto que sus miembros prefirieron realizar sus tareas sin reunirse. Los encargos partían de la junta de dirección para una o varias personas en concreto que realizaban el trabajo, rindiendo cuentas directamente a la Sociedad sin pasar por la comisión. De sus actas consta que se reunió una sola vez en 1811 y seis veces en 1812, especialmente entre los meses de junio y agosto. Su presidente, Carlos Montargis, solicitó a principios de 1812 que se ampliara el número de socios agregados ya que los que tenía eran insuficientes para desarrollar los trabajos encomendados. Por eso volvió a reorganizarse bajo la presidencia de Bernardo Iriarte y con Ventura de Arquellada como secretario. La asistencia osciló entre tres y seis miembros. Sus tareas se limitaron a la revisión de diversos inventos que solicitaban un privilegio de patente remitidos por el ministerio del Interior a la corporación para su examen y a elaborar el programa de premios de Artes y Oficios ideado a mediados de $1812^{54}$. Entre las actividades relacionadas con la materia de industria y artes pueden destacarse el examen de las máquinas existentes en el Montepío de Hilazas, con el objetivo de arreglar las deterioradas y volver a abrir la colección que había estado funcionando años anteriores, la revisión de un informe sobre el establecimiento de una Escuela de Mecánica para reintentar su apertura y otro sobre la libertad en las artes. También realizaron algunos dictámenes de expedientes remitidos por el ministerio del Interior ${ }^{55}$.

Por último, hay que mencionar que de esta época datan las memorias más interesantes elaboradas por los socios. Leídas por sus autores en diferentes juntas de dirección, varias de ellas merecieron la recomendación de su publicación. Sin embargo, la falta de fondos para acometer dicha empresa las dejó en el olvido, aunque alguna vio la luz en los años posteriores. Entre ellas se pueden destacar el Proyecto de establecimiento de escuelas de Agricultura de Antonio Sandalio Arias, la Memoria sobre los defectos de la legislación en cuanto a la agricultura de Claudio Boutelou, la Disertación sobre algunos estorbos de la Agricultura de Esteban

52 Jovellanos, G. M.: Informe de la Sociedad Económica de esta Corte al Real y Supremo Consejo de Castilla en el Expediente de ley agraria, Imp. Sancha, Madrid, 1795, pág. 117.

53 ARSEM: A/50, Libro de Actas de la Sección de Agricultura (1800-1823), Juntas de 17-4-1811 y 1 5-1811.

54 ARSEM: A/110/36, Juntas de 2-2-1811 a 22-2-1812 y ARSEM: A/41: Libro de Actas de la Clase de Artes y Oficios (1806-1815).

55 ARSEM: A/110/36, Juntas de 26-1-1811 a 23-3-1811. 
Boutelou y el Discurso sobre dar a conocer la Sociedad económica los males de la nación y los remedios a ellos de José Garriga ${ }^{56}$.

Durante los meses de enero a abril, la asistencia del director y subdirector a las juntas fue prácticamente continua, lo que da una idea del grado de implicación que mostraron en la primera etapa de su mandato. A partir de abril y hasta finales de junio, su presencia se hizo más esporádica, aunque sin dejar de concurrir en algunos momentos puntuales. Sin embargo, en el segundo semestre, desaparecieron completamente de la vida social de la corporación. El marqués de Almenara, sobrecargado de trabajo, tenía otras preocupaciones como para poder dedicarse en cuerpo y alma a la Matritense aunque tuviera esa intención cuando aceptó la dirección. A la complejidad de su ministerio, Almenara unió entre los meses de abril y julio de 1811 la cartera de guerra de forma interina. En esos meses, José I había viajado a Francia para asistir al bautizo del hijo de Napoleón, llevándose consigo al general O'Farrill, ministro de la Guerra. Mientras, un Consejo de Ministros se encargaría de gobernar de forma colegiada en ausencia del rey. Las frecuentes reuniones de este organismo en el que sus componentes se dedicaron casi exclusivamente a resolver las dificultades de tipo financiero del régimen y los problemas derivados de la insubordinación del gobernador militar de Madrid, el general Belliard, impidieron a los ministros fijar la vista en otras obligaciones distintas de la acción diaria de gobierno ${ }^{57}$. Meses más tarde, la propia ausencia del marqués de Almenara comisionado por el monarca a las provincias de Toledo y la Mancha, ponía otra vez a la Sociedad en la órbita de Manuel Romero que asumía la cartera de Interior de manera interina. El ministro de Justicia que, tan insensible se había mostrado anteriormente hacia la institución, volvía a comportarse de la misma manera. Por si esto fuera poco, la Matritense también se resentía de la falta del subdirector, José de Mazarredo, a quien una grave enfermedad impedía atender cualquier negocio público.

El asunto que concitaba la mayor preocupación de los socios era el Colegio de Sordomudos. Su deplorable estado había llegado a tal extremo que en la junta del sábado 2 de febrero de 1811 se planteó el cierre del colegio, porque ya no había dinero ni siquiera para alimentar a los colegiales, a pesar de que el alquiler del local donde estaba emplazado y los sueldos de los empleados hacía mucho tiempo que no se satisfacían. Las continuas peticiones al ministerio del Interior habían quedado sin respuesta y pronto la situación rozaría el dramatismo, si no se recibía dinero con la mayor brevedad. Una pequeña aportación del ministro de 1.920 reales conseguía prolongar su desenlace un mes más. Sólo la actitud desinteresada de algunos socios lograba que se mantuviera abierto. Los médicos Tomás Aldevó y Tomás García Suelto se ofrecieron a asistir a los niños gratuitamente y José Miguel Alea a actuar como maestro director después de la dimisión del anterior ${ }^{58}$. En el mes de marzo de

56 ARSEM: Idem, Juntas de 9-2-1811 a 23-3-1811 y 8-6-1811 a 27-7-1811.

57 Artola Gallego, M.: Los afrancesados, Ed. Turner, Madrid, 1976, págs. 205-206.

58 Tras el cese del maestro director, Juan de Dios Loftus, José Miguel Alea fue nombrado para dicho cargo de manera interina en 30-3-1811. ARSEM: A/110/36, Juntas de 22-12-1810 a 30-3-1811. 
1811, ya no se pudo esperar más. Las voces que reivindicaban una solución definitiva se hicieron más numerosas y convencieron a los que tenían una actitud dubitativa. La falta de fondos había llegado a tal extremo que los alumnos carecían de comida y vestidos. Por una parte, hicieron gestiones para que se les pudieran proporcionar ropas cuando el municipio de Madrid las repartiese entre los pobres, con motivo de la festividad de San José y, por otra, buscaron una institución que pudiera recoger a los niños. En este sentido, se eligió el Colegio de los Niños Doctrinos o de San Ildefonso al ofrecer su director una habitación en dicho centro, donde pudieran acomodarse los alumnos, que reunía las condiciones adecuadas para que continuase la enseñanza ${ }^{59}$. Mientras llegaba la respuesta del ministro a la propuesta de cierre del Colegio, los miembros de la Junta hicieron frente a la alimentación de los colegiales de su propio bolsillo. Finalmente, a primeros de mayo se realizó el traslado. Pero la situación no se arregló definitivamente, ya que la Matritense tenía la obligación de hacerse cargo de su manutención ${ }^{60}$. La preocupación por su estado continuó durante los meses siguientes. El desinterés con que fueron atendidos en el Colegio de San Ildefonso, a pesar de las buenas palabras, obligó a una nueva representación al ministro en junio de 1811. La última propuesta, ante la imposibilidad de continuar la enseñanza, exponía la conveniencia de que aprendiesen un oficio, con lo cual se eliminarían los gastos derivados del aprendizaje, a la vez que se les daba una oportunidad para poder valerse por sí mismos de cara al futuro. Agotados todos los recursos, los socios recurrieron al municipio de Madrid pero a principios de 1812 no se había resuelto satisfactoriamente la cuestión. Tuvieron que esperar hasta mayo de 1812 para que fueran recogidos en el Hospicio ${ }^{61}$.

La actitud del régimen afrancesado ante los planteamientos financieros de la Matritense estuvo basada desde el principio en la sinrazón. Por una parte, los organismos encargados de administrar los edificios públicos no dejaban de reclamar el cobro de los alquileres y, a su vez, el ministerio del Interior no proporcionaba los recursos necesarios para la supervivencia de los centros. Además, a muchos de estos establecimientos se les había privado de sus fuentes habituales de financiación por el expolio, el embargo y la confiscación de sus bienes, efectos y dinero. El mismo gobierno que ahogaba las finanzas de estas instituciones, se mostraba pasivo ante sus demandas, puesto que no tomaba ninguna decisión para tratar de mejorar su economía, como perdonar los alquileres o proporcionar otros locales de forma gratuita donde pudieran subsistir, tampoco los dotaba adecuadamente, ni respondía a las peticiones de cierre cuando la situación se había vuelto insostenible ${ }^{62}$.

59 ARSEM: Idem, Juntas de 9-3-1811 y 16-3-1811.

60 Sobre la estancia de los colegiales en el Colegio de San Ildefonso, véase EsPAdAs BuRGos, M.: «La Sociedad Económica Matritense y el hambre de 1812» en Las Reales Sociedades Económicas de Amigos del País y su obra, CSIC, San Sebastián, 1972, págs. 213-222.

61 ARSEM: A/110/36, Juntas de 22-6-1811, 29-6-1811, 21-9-1811 a 9-11-1811 y 29-2-1812.

62 La misma situación sufrieron los establecimientos de educación y beneficencia a cargo de la Junta de Damas. Sobre las Escuelas Patrióticas, véase NEgrín FAJARDO, O.: La educación popular en la Es- 
En el segundo semestre de 1811 el entusiasmo se fue apagando paulatinamente. La confianza que se había puesto en la dirección del marqués de Almenara no había producido los resultados apetecidos ni había respondido a las expectativas creadas. Todas las iniciativas y proyectos en los que los socios trabajaban de forma desinteresada chocaban con la misma dificultad, la financiera. A pesar de las buenas palabras, el ministerio no daba el dinero necesario. Los establecimientos educativos a cargo de la Sociedad, después del gran esfuerzo que se había hecho durante prácticamente cuatro años para que permanecieran abiertos, controlando escrupulosamente todos los gastos y estirando lo poco que poseían, agotaron finalmente todos los recursos y tuvieron que cerrarse por falta de medios.

Sin embargo, no todo se limitó a una crónica de desgracias financieras. El asunto que produjo el mayor desencuentro entre los afrancesados y el resto de socios se produjo por la «fuga» de Juan Pérez Villamil. Las gestiones realizadas en este sentido implicaron muy directamente a la Matritense y provocaron una escisión entre los socios. Este magistrado se encontraba cautivo en el depósito de Orthez (Francia) desde principios de 1809. Con la excusa de la necesidad de su presencia en Madrid para continuar la traducción de una obra de gran interés que se le había encargado años antes, la corporación solicitó su liberación al rey. Villamil después de conseguir el permiso de las autoridades francesas para volver a España, en vez de presentarse en Madrid, donde se le esperaba para concluir su trabajo, se fugó apareciendo en Cádiz. Al no dar esta mediación los resultados deseados, los miembros afrancesados trataron de justificarse ante José Bonaparte. Por segunda vez, intentaron el compromiso inequívoco de la Sociedad hacia el régimen josefino. Esto dio lugar a que éstos promovieran una medida que al resto le pareció excesiva: borrar del catálogo a Pérez Villamil, alegando que había tenido un comportamiento indigno. Sin embargo, esta propuesta finalmente no llegó a buen puerto debido a que la mayoría se opuso a la exclusión por no disponer de los datos suficientes para saber a ciencia cierta lo que había ocurrido ${ }^{63}$.

Esta cuestión puso de manifiesto lo que hasta entonces había permanecido oculto: la existencia de dos posiciones encontradas que dividían a los socios de la Matritense. Por una parte, aparecían los afrancesados convencidos, que no dudaban en usar el prestigio de la institución para lograr sus fines y, por otro, una mayoría de socios que no estaban dispuestos a dar un paso más en su compromiso frente a las autoridades y que secundaban cualquier propuesta de tipo político de muy mala gana, limitándose a cumplir lo estrictamente necesario. Algunos miembros actuaban por miedo a las represalias que podían sufrir por parte del gobierno y se daban cuenta de que la colaboración con los afrancesados no estaba dando

paña de la segunda mitad del siglo XVIII, UNED, Madrid, 1987 y respecto a la Inclusa y el Colegio de Niñas de la Paz, VIDAL GalACHE, B. y F.: Bordes y bastardos: una historia de la Inclusa de Madrid, Compañía Literaria, Madrid, 1994.

${ }^{63}$ Sobre la fuga de Juan Pérez Villamil, véase Domergue, L.: «Un épisode peu connu de la guerre de I'Indépendance: Don Juan Pérez Villamil et la traduction de Columelle» en Caravelle, 13, (1969), págs. 125-130. 
los resultados apetecidos. A pesar de haber transigido con los anteriores, secundando sus iniciativas y pese a sus esfuerzos por mantener la corporación abierta nunca conseguirían restablecer su esplendor.

Otro asunto que despertó un gran interés en la Sociedad Económica durante los últimos meses de 1811 consistió en buscar la manera de afrontar el problema de la carestía de cereales que estaba sufriendo Madrid durante ese invierno. En un año de mala cosecha, el abastecimiento de la capital empezó a resentirse. Según se adentraba la estación invernal poco a poco la situación se convirtió en dramática. La falta de un alimento básico para la dieta como el trigo provocó una creciente agitación social, manifestada en el asalto a las panaderías y en la turbulencia callejera. El escaso pan que se vendía, llamado "de munición» sólo estaba a disposición de los más ricos, mientras los pobres tenían que conformarse con el consumo de toda clase de mezclas de diferentes ingredientes como los «bocadillos de cebolla con harina de almortas, castañas y bellotas» ${ }^{64}$. Ante la espantosa situación que se avecinaba, el gobierno josefino intentó por todos los medios a su alcance paliar la miseria de los habitantes de la capital. En consecuencia, creó una comisión con el propósito de elaborar un proyecto para la instalación de un establecimiento de beneficencia que suministrase alimento a los pobres, financiado con suscripciones voluntarias y con las aportaciones de los concesionarios de las cuatro casas de juego que se habían instalado en Madrid durante esos meses ${ }^{65}$. Los socios de la Matritense, dentro de sus escasas posibilidades, contribuyeron como pudieron a aliviar las terribles circunstancias que se presentaron. Facilitaron a la Comisión de Socorros Públicos los informes y los expedientes que poseían sobre las comidas económicas que habían establecido en el invierno de 1803. A petición de la misma, cedieron parte de las instalaciones del Montepío de Hilazas para establecer allí unas cocinas donde se elaborasen alimentos para socorrer a los indigentes. Este local ya se había destinado a esta misión anteriormente, razón por la que estaba acondicionado para prestar este servicio. El socio Esteban Boutelou realizó, por encargo de la clase de Agricultura de la que formaba parte, una Memoria sobre las semillas que pueden reemplazar al trigo en la elaboración del pan a la que acompañaba una tabla sinóptica resumiendo las cantidades convenientes de semillas que debían emplearse en los sustitutivos. Los miembros de la comisión de Agricultura consideraron que esta obra podía tener gran interés en esos momentos críticos. La Sociedad la remitió al ministerio del Interior por si estimaba que debía imprimirse. Finalmente, el gobierno publicó la obra en extracto ${ }^{66}$.

64 El pan «de munición» se elaboraba a base de «trigo de la peor calidad, centeno, cebada, maíz y almortas». Pérez MoredA, V.: «La población madrileña» en Encıso ReCıO, L. M. (ed.): Actas del Congreso Internacional: El Dos de Mayo y sus precedentes, Madrid, 1992, págs. 403-404.

65 El Decreto de 19-11-1811 fijaba las condiciones para el establecimiento de beneficencia. Prontuario..., Tomo III, Imp. Real, Madrid, 1812, págs. 224-225.

66 Las iniciativas de la Matritense respecto al hambre de 1812, véase: Espadas Burgos, M.: Op. cit. 


\section{LA DIRECCIÓN DE MANUEL MARIA CAMBRONERO}

El 14 de diciembre de 1811 se procedió a la renovación de los puestos directivos de la corporación. Tanto el director como el subdirector cesantes no pudieron ser propuestos a la reelección porque alegaron incompatibilidad entre los cargos de responsabilidad de la Sociedad y los de miembros del gobierno, pues «teniendo este [el ministro] la iniciativa de las leyes, habia inconveniente en que manifestase su opinion como Director de la Sociedad, si luego esta veia que la resoluc ${ }^{n}$. de S.M. no era conforme á aquella opinion». Almenara y Mazarredo, ministros del gobierno de José I, habían aceptado el nombramiento el año anterior sin creer que pudiera surgir un conflicto de intereses por simultanear ambos cargos. Se daban cuenta de que su gestión no había respondido a las expectativas creadas al inicio de su mandato y seguramente, en privado, se les recriminaba su falta de sensibilidad hacia la institución. Por lo demás, la Sociedad siguió bajo la influencia de los afrancesados, ya que fue elegido como nuevo director Manuel María Cambronero, que pertenecía al Consejo de Estado, una de las instituciones más importantes del régimen josefino. A continuación, una vez hecha la representación correspondiente, el rey aprobó el nombramiento mediante el Decreto de 23 de enero de $1812^{67}$.

Cambronero, al igual que su antecesor, se mostró bastante activo y ejerció un control directo sobre la Matritense, pues apareció regularmente por las juntas desde el inicio de su mandato hasta el 1 de agosto de 1812, fecha en la que presidió las reuniones por última vez. Después de ese día cesó en la práctica su dirección, porque huyó de la capital con el resto de los partidarios de José Bonaparte, después de la batalla de Arapiles. El botánico Claudio Boutelou, director del Jardín Botánico, fue elegido subdirector. En su mandato tuvo que hacer frente a la continuidad de la institución tras el abandono del anterior.

Manuel María Cambronero procuró dar a su autoridad una orientación más política puesto que sus iniciativas tuvieron el sello del compromiso inequívoco con el soberano bonapartista. En este periodo una delegación de la Matritense visitó al rey y le invitó a formar parte de la institución como protector. Sus intentos por revitalizar la corporación, buscando la vuelta a una normalidad como la que había disfrutado antes de la guerra, quedaron en nada precisamente porque el régimen afrancesado se iba precipitando inevitablemente hacia el desastre. A pesar de todo la afluencia de socios gozó de regularidad e importancia y los trabajos se realizaron a un ritmo continuado.

A partir de marzo de 1812 la cuestión que ocupó casi de forma monográfica las juntas de la Matritense consistió en la preparación de la visita al rey José. El propósito aparente, según el director, para dicha audiencia estribaba en manifestar «la adhesion de este Cuerpo, para que S. M. se digne dispensarle su proteccion", es decir, un acto de respeto al soberano en el que se le entregarían las tareas reali-

${ }^{67}$ ARSEM: A/110/36, Juntas de 14-12-1811 a 25-1-1812. 
zadas, como se había realizado anualmente en tiempos de Carlos IV. Mediante esta disculpa, intentaba allanar oposiciones y evitar suspicacias. El director aprovechó la recepción que iba a ofrecer José por el cumpleaños de la reina Julia, el día 22 de mayo, para que el acto tuviera mayor boato y trascendencia. Ese día, el ministro del Interior, el marqués de Almenara presentó al rey la delegación de la Sociedad presidida por Manuel María Cambronero, compuesta por una nutrida representación de socios ${ }^{68}$. El secretario, Antonio Siles, leyó un Discurso preparado con este motivo y entregó al rey una Relación de las tareas realizadas desde 1809 y los seis tomos publicados de Memorias de la Sociedad ${ }^{69}$. Finalmente, como había previsto Cambronero, se convirtió en un acto de propaganda afrancesado que comprometió a la institución, puesto que las palabras pronunciadas se publicaron al día siguiente en la Gazeta. En el Discurso, la Sociedad por propia iniciativa pedía al soberano que convocase Cortes Generales. Estas manifestaciones formaban parte de una campaña propagandística que los afrancesados estaban desarrollando en esos días para intentar seguir a flote cuando ya el régimen estaba precipitándose al abismo, ahogado por las dificultades financieras, la administración inoperante, la resistencia de buena parte del país y la desobediencia de los mandos militares.

Durante el mes de mayo de 1812, se produjeron diversas iniciativas que trataban de crear una opinión favorable a la convocatoria de Cortes. Diferentes instituciones recibidas por el monarca durante esos días se habían manifestado en este sentido. Entre otros, el 7 de mayo una diputación encabezada por el Corregidor de Madrid, insistió en este aspecto. El 14 de mayo el Consejo Privado de José Bonaparte se reunió para debatir su idoneidad. A él fueron invitados algunos miembros del Consejo de Estado que estaban encargados de estudiar este asunto desde hacía un año. Todos ellos se mostraron a favor de actuar rápidamente, al considerar que constituía el medio más eficaz para lograr la pacificación del país. En el momento más álgido de la campaña, que incluyó la edición de folletos y la inserción de artículos en la Gazeta, la Sociedad Matritense se presentó ante el monarca, sumándose a los esfuerzos ${ }^{70}$.

El contenido del Discurso, redactado por Manuel María Cambronero, mezclaba las adulaciones con las reivindicaciones políticas. Comenzaba elogiando a José I, al que consideraba un rey capaz de remover «los obstáculos que se oponen á las luces y las innovaciones provechosas». El soberano no se encontraría solo en este empeño. La Matritense siempre estaría dispuesta a suscribir las políticas que impulsasen el desarrollo del país y a trabajar al lado de las iniciativas reformistas. No obstante, para ponerse en movimiento era indispensable acabar con la guerra que actuaba como freno para acometer la obra con éxito. La solución que sugería la Sociedad Económica como la más adecuada para lograr la paz se

68 ARSEM: Idem, Juntas de 4-4-1812 y 20-5-1812.

69 Sobre la Relación de las tareas de la Sociedad, véase DemERson, J.: Op. cit., págs. $43-64$.

70 Artola Gallego, M.: La España de Fernando VII, RBA, Barcelona, 2005, pág. 282. 
señalaba a continuación: «La nacion solamente, si conoce el empleo útil de sus fuerzas, puede evitar tanta ruina (...) Que el voto general se pronuncie legalmente y de un modo enérgico; $y$ entonces el consejo de todos los buenos españoles, que no pueden tener mas que un solo interes, podrá asegurar la existencia amenazada de la nacion, y la integridad é independencia». A continuación se atrevía a pedir directamente al monarca: «Cortes, Señor, cortes generales». La institución, elevándose en portavoz de una opinión general, se consideraba autorizada para expresar una idea que podía suscribirse de manera unánime y que habían sugerido también otras instituciones recibidas por el soberano los días anteriores ${ }^{71}$.

Con la campaña orquestada desde el propio gobierno a favor de la convocatoria de Cortes, el régimen josefino se agarraba a la última esperanza que podría salvar la integridad de la nación. Sin embargo, la asamblea que reivindicaban los afrancesados poco tenía que ver con la reunida en Cádiz. Su competencia legislativa se restringía mucho si se comparaba con la que definía la Constitución de 1812, proclamada dos meses antes. El régimen josefino se encontraba en una situación bastante incierta, puesto que actuaba de espaldas a lo que ocurría en la España no ocupada y estaba desprestigiado por las artimañas de Napoleón para incautarse de las provincias al norte del Ebro. Esta campaña únicamente se podía interpretar como una maniobra desesperada de propaganda de los afrancesados para mantener una ficción de soberanía e independencia que no estaban en condiciones de defender ${ }^{72}$.

Aún así, a pesar de que la institución había sido utilizada para las intrigas políticas, cediendo ante la presión de los afrancesados y comprometiendo su buen nombre, algunos miembros se dejaron llevar por el aparente éxito de la visita al soberano. Los socios creyeron entusiasmados que podía ser el acicate que lograría el restablecimiento de la normalidad en la institución. Por eso, acto seguido, propusieron que el rey se incorporase a la Sociedad Económica siguiendo la línea tradicional de respetuoso comportamiento hacia la monarquía. De hecho, José I fue admitido el 30 de mayo de 1812 encabezando su Catálogo ${ }^{73}$.

Aprovechando el impulso creado, la Sociedad volvió a plantearse la vuelta a la celebración de los certámenes anuales de premios, volcando todos los esfuerzos en elaborar un programa. Los socios creían que de esta manera podrían reanimar a la Matritense, puesto que «haciendo ver al pubco. que en medio de los trastornos que trae consigo una revolucion, no há dexado un momento de meditar y trabajar seriam $^{\text {te }}$. en promover los obgetos de su instituto". Asimismo, no era desdeñable el efecto propagandístico que podía representar el retorno visible a una aparente normalidad de cara a la opinión pública. Las propuestas se elaboraron en la clase de Agricultura que llevaba funcionando desde hacía más de un año y en la de Artes

71 Gazeta de Madrid, 23-5-1812, pág. 582.

72 Mercader Riba, J.. José Bonaparte... Estructura del Estado..., págs. 33-36.

73 ARSEM: A/110/36, Junta de 30-5-1812. 
que se reorganizó al efecto bajo la presidencia de su socio más antiguo, Bernardo Iriarte. Las dos comisiones presentaron sus proyectos a la corporación para su discusión en las juntas siguientes, aprobándose definitivamente la convocatoria a finales de junio de $1812^{74}$. El programa establecía una continuidad con los premios ofrecidos hasta 1807, imbuidos por el pensamiento ilustrado, aunque también se hacía eco de preocupaciones más cercanas a los tiempos presentes, al dar gran importancia a los problemas de la legislación, intentando abrir un debate respecto a los aspectos concretos que se señalaban en la convocatoria. Los socios procuraban dar la sensación de que querían tener una proyección hacia el futuro a pesar de los acontecimientos de la guerra. Ni siquiera dio tiempo a insertar el anuncio de los premios en la Gazeta, pues el 22 de julio de 1812 el ejército francés fue derrotado en Arapiles, cerca de Salamanca, por las tropas combinadas hispano-inglesas al mando del duque de Wellington. Así terminó el último deseo de los socios afrancesados para aprovechar el crédito de la Matritense para prestigiar la política del régimen josefino. Igual que prácticamente todas las iniciativas anteriores, quedó en una tentativa inacabada sin ninguna trascendencia.

\section{EL FIN DE LA DOMINACIÓN FRANCESA}

En los primeros días del mes de agosto de 1812 el desconcierto cundió entre los afrancesados. Después de la batalla de Arapiles, las tropas aliadas se dirigieron hacia Madrid. Mientras tanto, la corte de José apresuraba su marcha rumbo a Valencia. El rey salió el día 10 de agosto, dejando una pequeña guarnición en el Retiro. Una riada de personas comprometidas con el régimen huyó junto al convoy francés, entre ellas algunos activos miembros de la Sociedad Matritense. Dos días más tarde, Wellington entró en la capital, siendo recibido con entusiasmo ${ }^{75}$.

Las reuniones que se celebraron durante el periodo de la liberación de Madrid, entre agosto y octubre de 1812, fueron escasas y con poca concurrencia de socios. Se limitaron a una a finales de agosto, otra en septiembre y tres en octubre. A pesar de la incertidumbre, la institución tenía que seguir funcionando, por eso en las juntas se plantearon varias cuestiones que hubo que resolver sobre la marcha. Gracias a que el subdirector Claudio Boutelou y los restantes directivos que permanecieron en Madrid no quisieron desentenderse, la corporación logró salir de la crisis. La primera de las juntas, el 22 de agosto, se celebró en la propia casa del subdirector $^{76}$. Uno de los problemas al que tenían que hacer frente, de máxima importancia, radicaba en la huida en el convoy francés, de quien ocupaba el cargo de

74 ARSEM: Idem, Juntas de 30-5-1812 a 27-6-1812.

75 Mercader RiBA, J.: José Bonaparte... Historia Externa..., págs. 326-327.

76 ARSEM: A/110/38, Libro de Actas de las Juntas de la Sociedad (julio 1812-junio 1815), Junta de 22-8-1812. 
tesorero interino, José Ignacio de Acevedo, marqués de Uluapa, sin haber entregado las cantidades y efectos que custodiaba ${ }^{77}$.

Desaparecidos los socios más comprometidos con el gobierno afrancesado, los asistentes a las juntas creyeron que había llegado el momento para entrar en contacto con los resistentes gaditanos. El secretario segundo, José Villanova y Jordán, presentó una moción para felicitar al socio Juan Pérez Villamil que fue aprobada. Éste había conseguido la libertad gracias a la mediación de la institución un año antes y acababa de incorporarse como miembro de la Regencia instalada en Cádiz, sustituyendo al conde de la Bisbal. El momento era inmejorable para intentar sondear a las autoridades del bando patriótico aprovechando la ausencia de franceses en la capital ${ }^{78}$.

Sin embargo, la calma duró poco. Una incertidumbre hacia el futuro se extendió después de que las tropas del ejercito aliado abandonaran Madrid. El día 1 de septiembre de 1812 Wellington había salido de la ciudad dejando una pequeña guarnición que posteriormente retiró a finales de octubre. El general inglés temía que los franceses le cortasen las comunicaciones con sus bases portuguesas. Los galos habían conseguido reorganizar un ejército en el Duero que le amenazaba directamente. La población quedó desamparada, regida únicamente por las autoridades municipales al mando de Pedro Sainz de Baranda, que lograron mantener el orden $^{79}$. No obstante, precisamente por la ausencia de autoridades de uno y otro bando, abandonada la ciudad por todos, en el mes de octubre las juntas de la Sociedad tuvieron mayor concurrencia. Incluso se abordaron cuestiones que no se habían resuelto desde tiempo atrás y que estaban más cercanas a las preocupaciones de los socios presentes. Aquellos que se habían mostrado reticentes al control de la institución por los afrancesados o que soportaban su presencia con disgusto, ahora intentaban tomar las riendas de la institución. En estas sesiones se aprobaron mociones para el restablecimiento de la Escuela de Taquigrafía, que llevaba cerrada desde 1808 a pesar de las reiteradas solicitudes hechas al gobierno josefino para su reapertura y para la reinstalación del Colegio de Sordomudos, cuyo cierre había causado un sentimiento de impotencia en algunos miembros de la institución al constatar su fracaso a pesar de los esfuerzos realizados. Además, surgieron iniciativas a favor de la recolocación de la colección de máquinas y los enseres de la Sociedad en los locales del Montepío de Hilazas y para la recuperación de los fondos incautados de forma irregular ${ }^{80}$.

77 Consistían en 1.487 reales de dinero en efectivo y otros efectos. A pesar de que se intentó recuperar por medio de una reclamación judicial en 1814, todas las gestiones resultaron infructuosas. ARSEM: Idem, Junta de 21-5-1814.

78 Juan Pérez Villamil se había incorporado a la tercera regencia el 29-9-1812. ToRENo, conde de: Op. cit., Tomo VI, pág. 45.

79 Sarrablo Aguareles, E.: «La vida en Madrid durante la ocupación francesa» en // Congreso Histórico Internacional de la Guerra de la Independencia y su época, Inst. Fernando el Católico, Zaragoza, 1964, pág. 209.

80 ARSEM: A/110/38, Juntas de 10-10-1812 y 24-10-1812. 
El día 2 de noviembre pasó José por Madrid procedente de Valencia, permaneciendo en la capital cuarenta y ocho horas. Estaba al mando del ejército imperial en persecución de las tropas hispano-británicas que se replegaban a toda prisa hacia Portugal ante el empuje francés. Emprendió el regreso el 23 de noviembre, y realizó su entrada el 3 de diciembre. A partir de esa fecha poco a poco retornó el resto de autoridades civiles y funcionarios públicos que estaban desparramados entre Zaragoza y Valencia. La llegada masiva de los afrancesados no se completó hasta el 25 de febrero de $1813^{81}$.

En los dos últimos meses de 1812 sólo se celebró una junta en noviembre, hasta que se reanudaron el 16 de enero de 1813. Para esta primera reunión del año se convocaron las elecciones anuales. Los directivos habían cumplido su mandato a finales del año anterior y no era conveniente que se prolongase la interinidad, que ocasionaba retrasos e indecisiones en el funcionamiento diario de la institución. Estas votaciones ya no fueron controladas por el grupo afrancesado, desaparecido de la Matritense prácticamente desde agosto de 1812. La elección recayó en Claudio Boutelou que pasó a ocupar la dirección y Manuel de la Viña la subdirección (dos personas con perfil político de menor compromiso con el régimen josefino). El primero aportaba su prestigio como científico y su buen hacer al haber ejercido la dirección de manera interina en los meses anteriores y el segundo, comerciante, había formado parte del equipo municipal madrileño como regidor bajo las órdenes de Pedro Sainz de Baranda en los meses de la ocupación anglo-española ${ }^{82}$.

La nueva ocupación francesa de Madrid volvió a atraer a la Sociedad a algunos de los afrancesados que habían retornado de Valencia. En estos primeros meses del año de 1813 todavía tuvieron tiempo de hacer los últimos guiños al gobierno josefino. Primero, solicitando al rey José la aceptación del nuevo director, Claudio Boutelou, que se hizo a toda prisa en la misma sesión de la convocatoria de las elecciones, redactando la representación correspondiente, firmada por los concurrentes. Varios días más tarde, el marqués de Almenara remitió el Decreto en el que se aprobaba la elección por el monarca. Aquí finalizaron los contactos del ministro con la corporación. Por otro lado, como último recurso para resolver la penuria financiera, determinaron solicitar al soberano los 3.000 reales que le correspondía aportar como protector según los Estatutos. En la representación, dirigida al intendente de la Corona, respetuosamente le incitaban a que colaborase a la obra de la Matritense mediante su contribución anual. La petición fue aprobada en la junta de 13 de marzo de 1813, aunque ya era demasiado tarde para pretender que el monarca fuera sensible a sus necesidades, cuando su reinado en España estaba a punto de finalizar. También se requirió al marqués de Almenara por enésima vez que incluyese a la institución en los presupuestos mensuales por los 1.500 reales aprobados desde 1810 para gastos de secretaría y juntas, con objeto de allegar algún recurso de última hora ${ }^{83}$.

81 Mercader Riba, J.: José Bonaparte... Historia Externa..., págs. 355-356 y 363.

82 ARSEM: A/110/38, Junta de 16-1-1813.

83 ARSEM: Idem, Juntas de 30-1-1813 y 13-3-1813. 
José Bonaparte abandonó Madrid el 17 de marzo de 1813, para no volver más. Junto a él, huyó una riada de personas comprometidas políticamente con su régimen, que se incorporaron paulatinamente a los distintos convoyes organizados en los días siguientes. Los miembros del gobierno, con el rey a la cabeza, se dirigieron hacia Valladolid, mientras otros afrancesados tomaron el camino de Burgos. El 21 de junio el ejército imperial presentó batalla en los alrededores de Vitoria contra las tropas anglo-españolas al mando del duque de Wellington. La derrota francesa fue completa. La retirada de los militares galos hacia la frontera provocó una desbandada generalizada, en medio de la confusión y el pánico. Abandonados a su suerte, los que escapaban pudieron ganar la frontera después de grandes penalidades ya que muchos de ellos se vieron obligados a abandonar sus pertenencias, saqueadas por los vencedores. El reinado de José en España había terminado84.

Las reuniones celebradas entre los meses de enero y marzo, aunque regulares, registraron una asistencia escasa, sin que apenas se trataran temas de interés. Las comisiones de Agricultura e Industria habían interrumpido sus sesiones desde el verano anterior y no volvieron a reanudarse hasta finales de 1813. Únicamente tuvieron tiempo para revisar una memoria de Nicolás Massé, comandante del primer batallón del tren de equipajes del ejército francés, que había inventado un molino portátil de campaña ${ }^{85}$. La última junta de la Matritense bajo la dominación francesa se celebró el 20 de marzo de 1813. En esos mismos días ya había comenzado la evacuación de la capital que se completó el 27 de mayo, cuando los últimos recibieron la orden de partir de la ciudad. Estos dos meses se vivieron en la ciudad con gran inquietud por el miedo a los excesos que podían cometer los soldados napoleónicos en su repliegue, aunque los miembros del equipo municipal, que constituían el único poder reconocido, lograron mantener el orden. A partir del 1 de junio comenzaron a llegar las primeras avanzadas del ejército español y con él las nuevas autoridades constitucionales, entre las que se encontraba el Jefe Político de Madrid, Joaquín García Domenech. Las juntas de la institución se reanudaron el 5 de junio de 1813, pero ya desde otra perspectiva, porque las circunstancias habían cambiado. Había que iniciar contactos para congraciarse con los nuevos mandatarios políticos recién instalados ${ }^{86}$.

\section{CONCLUSIONES}

Las Sociedades Económicas de Amigos del País sobresalieron en el panorama científico e intelectual de la llustración española por su novedad y sus características institucionales. Desde su nacimiento contaron con el apoyo oficial que favoreció su implantación. En su seno se realizaron algunos de los estudios más completos sobre los problemas económicos del Antiguo Régimen. Sus socios creían

\footnotetext{
84 Mercader Riba, J.: José Bonaparte... Historia Externa..., págs. 367-376.

85 ARSEM: A/110/38, Junta de 20-3-1813.

86 ARSEM: Idem, Juntas de 5-6-1813 y 19-6-1813.
} 
que estas corporaciones estaban llamadas a fomentar la modernización económica que necesitaba el país. La Matritense, fundada en 1775, se vio favorecida por su cercanía al poder político. Su programa se desarrolló en los ámbitos educativo, económico y social. Colaboró activamente para difundir el ideario ilustrado durante el reinado de Carlos III. En la época de Carlos IV continuó dedicada a sus actividades para el progreso de las «luces», aunque con menor dinamismo.

La tranquilidad que gozaba fue puesta a prueba a partir del año de 1808. Los acontecimientos que se sucedieron ese año y durante los cinco siguientes trastocaron la institución de una manera intensa. La dominación francesa marca un descenso en las actividades de la corporación. Sin embargo, pudo mantenerse abierta a pesar de todos los avatares de la guerra de la Independencia, lo cual indica la persistencia y obstinación de sus integrantes para garantizar su existencia. En estos años la vida de la Sociedad Económica está marcada por la inestabilidad sufrida en la ciudad de Madrid, ya que, por un lado, las sucesivas ocupaciones de los ejércitos de los bandos en conflicto repercutieron de forma importante en sus actividades, por otro, definió sus relaciones con las fuerzas políticas de cada momento y, por último, determinó la mayor o menor afluencia de sus socios.

Básicamente, el crédito de la institución estaba asentado en tres pilares fundamentales: el apoyo oficial, la financiación adecuada y la asociación. La carencia de alguno de ellos marcaba la diferencia entre el auge o la decadencia de la corporación. En los momentos que pudo mantener su independencia del poder político sus actividades se resintieron por la escasez económica y la falta de socios. La protección por parte del Estado josefino estimuló la renovación de sus tareas y la aparición de muchos de sus miembros, dispuestos a trabajar a favor de los intereses del nuevo régimen. Sin embargo, esta estrategia de captación de socios no dio los resultados deseados por falta de un apoyo financiero eficaz por parte de la Administración bonapartista. Todos los proyectos emprendidos fracasaron uno tras otro, a pesar de las esperanzas puestas en que el amparo del gobierno lograría sacar a la corporación de su letargo.

En estos años, las relaciones con los mandatarios políticos estuvieron marcadas por los altibajos. Tras unos comienzos dubitativos en los que los socios no supieron muy bien a que atenerse, enseguida reaccionaron intentando establecer contactos con el poder establecido. La propuesta de elaborar un Elogio al nuevo rey, Fernando VII y la intención de ser recibidos por Murat caracterizan una línea de comportamiento definida por la idea del respeto a las autoridades políticas. Sin embargo, esta aproximación no constituyó, en la mayoría de las ocasiones, tanto una cuestión de sintonía como de supervivencia.

En dos momentos, estos acercamientos partieron de las propias autoridades, antes de que la Matritense intentara establecerlos. En el caso de la Junta Central, se estableció una breve correspondencia durante el periodo en que estuvo instalada en Aranjuez. No obstante, las circunstancias políticas impidieron que adquiriese una profundidad que podría haber dado buenos resultados. La segunda 
ocasión surgió después de la crisis provocada por la batalla de Talavera en septiembre de 1809. En ese momento, los afrancesados se dieron cuenta de la necesidad de prestigiar su política tratando de lograr nuevos adeptos a su causa. Con este fin, creyeron que mediante la implantación de un programa reformista podrían lograr la captación de ciertas minorías, sensibles a los proyectos modernizadores. En este aspecto se centró la estrategia de protección a favor de la Sociedad Matritense.

En los años de la dominación francesa, diversas personalidades desfilaron por las reuniones de la corporación madrileña. Entre ellas, destacó especialmente, José Martínez de Hervás, marqués de Almenara, que se convirtió durante mucho tiempo en el alma de la institución, a pesar de que sus tareas políticas impidieron que pudiera dedicarse a ella todo lo que en un principio había pretendido. De todas maneras logró controlarla, accediendo a su puesto más alto. Su dirección produjo un cierto impulso en la institución que favoreció el planteamiento de algunas iniciativas de renovación. Su estrategia se basó en dos aspectos principales: la protección del gobierno y la reanudación de las tareas interrumpidas por la guerra. Tanto una como otra resultaron insuficientes para sacar a la institución de su inercia, más que nada por la falta de unas circunstancias propicias para plantear un nuevo florecimiento.

Aunque contó con la protección del gobierno, ésta fue más nominal que real, ya que no llegó a materializarse en un apoyo financiero eficaz como se reclamaba desde la corporación. Las dificultades de la Hacienda josefina impidieron que las subvenciones públicas se recibieran de forma regular. También la propia voracidad del Estado bonapartista para allegar recursos provocó que sus finanzas se resintiesen todavía más de lo que en principio podía preverse. El recurso a la confiscación utilizado por los dominadores y su insensibilidad hacia los problemas financieros que tenía la corporación para mantener los establecimientos educativos y de beneficencia, condujeron a una penuria económica que únicamente produjo desengaños y sinsabores en aquellos que confiaron en los afrancesados como medio para subsistir.

Por otra parte, el restablecimiento de las actividades se concretó principalmente en el desarrollo de tres cuestiones: la reorganización interna, la elaboración de un plan financiero y la afluencia de socios. A pesar de los esfuerzos derrochados, únicamente la incorporación de nuevos miembros tuvo un cierto éxito. Los otros dos proyectos quedaron en tentativas inacabadas; el primero, por la excesiva lentitud con la que se acometió la reforma de los Estatutos y, el segundo, por la falta de respuesta del gobierno josefino a las inquietudes reclamadas desde la institución.

La renovada incorporación de socios repercutió, en principio, de manera positiva en la Matritense puesto que aportaron nuevas ideas, ayudaron en las tareas e intentaron que la protección del gobierno se materializara en recursos concretos. No obstante, a la vez, provocó una división en el seno de la corporación que per- 
maneció oculta la mayoría del tiempo y sólo salió a relucir en algunos momentos señalados, en los cuales se produjeron conflictos directos entre los dos bandos.

La comisión que acometió el plan de reforma de los Estatutos vio con claridad las dificultades que habían provocado la decadencia de la Sociedad Económica. Por tanto, acometió la reforma, buscando una nueva organización que evitase la recaída en errores anteriores. Para ello, propuso que la institución se deshiciera de las actividades educativas y de beneficencia debido al lastre que suponían en su economía y al derroche de esfuerzos empleados para la resolución de los problemas que generaba su gestión. Además, el mantenimiento de estos establecimientos obligaba a un alineamiento con el poder para lograr la protección financiera y, por añadidura, esto redundaba en la pérdida de la independencia y la libertad, cuestión muy valorada por los socios. En consecuencia, sus labores debían ceñirse al fomento de la economía de la nación y al asesoramiento a otras instituciones y particulares que lo solicitaran. Así volverían a concurrir sus miembros a las reuniones y a resurgir los trabajos en pos del progreso, lo cual había logrado llevarla en el pasado al puesto preponderante que añoraban ahora sus socios.

A pesar de las dificultades económicas, la colaboración con el gobierno no siempre resultó infructuosa. La función de asesoramiento al ministerio del Interior, organismo que tenía asignadas las competencias de fomento en el régimen bonapartista, se desarrolló con normalidad. Las diferentes cuestiones remitidas tuvieron una respuesta inmediata por parte de la institución. Esta faceta se concretó en la resolución de expedientes, el examen de inventos y la aportación de sus conocimientos.

Por último, habría que mencionar brevemente el papel de esta corporación dentro del entramado político afrancesado. Durante la dominación napoleónica la reputación de la Sociedad Económica se empleó como un medio de propaganda para prestigiar la política josefina. En cierto modo, se convirtió en una cuestión de oportunismo político en el que la apropiación del mensaje renovador y patriótico de los «Amigos del País» servía a los intereses del régimen.

La primera ocasión se produjo tras la crisis de Talavera cuando el gobierno josefino tomó conciencia de su impopularidad. La reanudación de las actividades de la Matritense se situó entre las diversas iniciativas que se pusieron en práctica para mejorar su imagen de cara a la opinión pública. En la práctica, hasta entonces había permanecido olvidada del gobierno, cuando no mirada con un especial recelo. Por tanto, la estrategia de acercamiento de los afrancesados se concretó en la concesión de determinados favores de especial contenido propagandístico: a disposición de la corporación se puso una nueva sala de reuniones acorde a sus necesidades, obtuvo la protección del soberano y se le concedió una subvención mensual para poder desarrollar sus trabajos. Para la pertinente publicidad del acontecimiento se insertó una nota en la Gazeta, en la que se daba cuenta de su restablecimiento, gracias a la «bondad» del soberano. 
El segundo momento se rodeó todavía más de los elementos de propaganda política que necesitaba el régimen bonapartista para intentar salir a flote cuando ya caminaba directamente hacia el desastre. La utilización de la voz de la corporación para pedir al rey la convocatoria de Cortes entraba dentro de una campaña orquestada desde el propio gobierno de cara a crear en la opinión pública una acogida favorable a esta cuestión. Los afrancesados cifraban su última esperanza para lograr la pacificación del país en la formación de una asamblea que acometiese las reivindicaciones políticas. El empleo de la reputación de la corporación en provecho de este proyecto únicamente ocasionó consecuencias indeseadas para aquellos que se vieron obligados a participar en el acto, puesto que adquirieron una notoriedad que les pasó factura a posteriori.

En resumen, los años de la dominación francesa quedaron como una sucesión de diferentes tentativas para sacar a la Sociedad Económica de su letargo. La crónica de la institución es un reflejo de los avatares del régimen bonapartista para sobrevivir en estos años. La crisis que, a todos los niveles, provocó la guerra de la Independencia repercutió de forma considerable en las actividades de la corporación, puesto que la inestabilidad de una ciudad ocupada no proporcionaba la tranquilidad necesaria para desarrollar sus objetivos. Para poder sobrevivir necesitó congraciarse con los distintos mandatarios políticos para recabar el apoyo oficial necesario para el sostenimiento de las actividades educativas y asistenciales que desarrollaba. No obstante, el control de la institución por parte de los partidarios de José Bonaparte no resolvió los problemas. Por su parte, sus tareas se vieron disminuidas por la falta de socios, unos porque habían huido de Madrid y otros para evitar relacionarse con los afrancesados. Además, le faltó una financiación adecuada a causa de las dificultades del gobierno josefino para hacer frente a todas las responsabilidades de un Estado, ahogado como estaba por la necesidad de sustentarse con la ayuda del ejército imperial. Al final, a pesar de las dificultades para mantener la institución abierta, quedaron los esfuerzos de unos pocos socios, escarmentados por la actuación de los afrancesados, que habían utilizado su prestigio para sus intereses, pero sin lograr resolver las cuestiones que la vida diaria de la Matritense planteaba. 